\title{
Hepatic deletion of $\mathrm{p} 110 a$ and $p 85 a$ results in insulin
}

\author{
resistance despite sustained IRS1-associated
}

\section{phosphatidylinositol kinase activity [version 1; peer review: 3}

\section{approved with reservations]}

\author{
Aditi Chaudhari ${ }^{1,2}$, Katarina Ejeskär ${ }^{3}$, Yvonne Wettergren ${ }^{4}$, C. Ronald Kahn ${ }^{5}$, \\ Victoria Rotter Sopasakis (D1, 1,5
}

1Wallenberg Laboratory, Department of Molecular and Clinical Medicine, University of Gothenburg, Gothenburg, Sweden
2Department of Physiology, University of Gothenburg, Gothenburg, Sweden
3Institute of Health and Education, Translational Medicine, University of Skövde, Skövde, Sweden
${ }^{4}$ Department of Surgery, University of Gothenburg, Sahlgrenska University Hospital/Östra, Gothenburg, Sweden
5Joslin Diabetes Center and Harvard Medical School, One Joslin Place, Boston, MA, USA
6Department of Clinical Chemistry and Transfusion Medicine, University of Gothenburg, Gothenburg, Sweden

V1 First published: 30 Aug 2017, 6:1600

https://doi.org/10.12688/f1000research.12418.1

Latest published: 05 Jun 2018, 6:1600

https://doi.org/10.12688/f1000research.12418.2

\section{Abstract}

Background: Class IA phosphatidylinositol-4,5-bisphosphate 3-kinase (PI3K) is an integral mediator of insulin signaling. The p110 catalytic and $\mathrm{p} 85$ regulatory subunits of PI3K are the products of separate genes, and while they come together to make the active heterodimer, they have opposing roles in insulin signaling and action. Deletion of hepatic $p 110 a$ results in an impaired insulin signal and severe insulin resistance, whereas deletion of hepatic p85a results in improved insulin sensitivity due to sustained levels of phosphatidylinositol $(3,4,5)$-trisphosphate. Here, we created mice with combined hepatic deletion of p110a and p85a (L-DKO) to study the impact on insulin signaling and whole body glucose homeostasis.

Methods: Six-week old male flox control and L-DKO mice were studied over a period of 18 weeks, during which weight and glucose levels were monitored, and glucose tolerance tests, insulin tolerance test and pyruvate tolerance test were performed. Fasting insulin, insulin signaling mediators, PI3K activity and insulin receptor substrate (IRS)1-associated phosphatidylinositol kinase activity were examined at 10 weeks. Liver, muscle and white adipose tissue weight was recorded at 10 weeks and 25 weeks.

Results: The L-DKO mice showed a blunted insulin signal downstream of PI3K, developed markedly impaired glucose tolerance, hyperinsulinemia and had decreased liver and adipose tissue weights. Surprisingly, however, these mice displayed normal hepatic glucose

\section{Open Peer Review}

\begin{tabular}{lccc} 
Approval Status & ? & \\
& 1 & 2 & 3 \\
\hline version 2 & & & $?$ \\
(revision) & view & view & view \\
05 Jun 2018 & ? & ? & ? \\
version 1 & $?$ & $?$ & $?$ \\
30 Aug 2017 & view & view & view
\end{tabular}

1. James R. Woodgett iD, Sinai Health System \& University of Toronto, Toronto, Canada Prital Patel, Sinai Health System \& University of Toronto, Toronto, Canada

2. Lily Q. Dong, University of Texas Health at San Antonio, San Antonio, USA

3. Richard Z. Lin, Stony Brook School of Medicine, Stony Brook, USA

Lisa Ballou, Stony Brook School of Medicine, Stony Brook, USA 
production, normal insulin tolerance, and intact IRS1-associated phosphatidylinositol kinase activity without compensatory upregulated signaling of other classes of PI3K. Conclusions: The data demonstrate an unexpectedly overall mild metabolic phenotype of the L-DKO mice, suggesting that lipid kinases other than PI3Ks might partially compensate for the loss of p110a/p85 a by signaling through other nodes than Akt/Protein Kinase B.

\section{Keywords}

phosphatidylinositol-4, 5-bisphosphate 3-kinase, p110, p85, insulin receptor substrate, insulin resistance, glucose intolerance
Any reports and responses or comments on the article can be found at the end of the article.

Corresponding author: Victoria Rotter Sopasakis (victoria.rotter@clinchem.gu.se)

Author roles: Chaudhari A: Formal Analysis, Validation, Writing - Original Draft Preparation, Writing - Review \& Editing; Ejeskär K: Validation, Writing - Review \& Editing; Wettergren Y: Validation, Writing - Review \& Editing; Kahn CR: Conceptualization, Funding Acquisition, Resources, Supervision, Writing - Review \& Editing; Rotter Sopasakis V: Conceptualization, Formal Analysis, Funding Acquisition, Investigation, Methodology, Project Administration, Resources, Supervision, Validation, Writing - Original Draft Preparation, Writing - Review \& Editing

Competing interests: No competing interests were disclosed.

Grant information: This work was supported by the Swedish Research Council (VRS), the Sahlgrenska Academy Foundation (VRS), the Magnus Bergvall foundation (VRS), and the Wilhelm and Martina Lundgren Foundation (VRS). The work was also supported by NIH grant DK055545 (CRK).

The funders had no role in study design, data collection and analysis, decision to publish, or preparation of the manuscript.

Copyright: ( 2017 Chaudhari A et al. This is an open access article distributed under the terms of the Creative Commons Attribution License, which permits unrestricted use, distribution, and reproduction in any medium, provided the original work is properly cited. Data associated with the article are available under the terms of the Creative Commons Zero "No rights reserved" data waiver (CC0 1.0 Public domain dedication).

How to cite this article: Chaudhari A, Ejeskär K, Wettergren $Y$ et al. Hepatic deletion of p110a and p85a results in insulin resistance despite sustained IRS1-associated phosphatidylinositol kinase activity [version 1; peer review: 3 approved with reservations] F1000Research 2017, 6:1600 https://doi.org/10.12688/f1000research.12418.1

First published: 30 Aug 2017, 6:1600 https://doi.org/10.12688/f1000research.12418.1 


\section{Introduction}

Class IA phosphatidylinositol-4,5-bisphosphate 3-kinase (PI3K) is a central mediator of a number of membrane receptor signaling pathways, including the insulin signaling pathway ${ }^{1,2}$. Following receptor activation by insulin, PI3K binds to tyrosinephosphorylated amino acids of the insulin receptor substrates (IRS), resulting in PI3K activation and the formation of phosphatidylinositol $(3,4,5)$-trisphosphate $\left(\mathrm{PIP}_{3}\right)$. $\mathrm{PIP}_{3}$ has high affinity for the pleckstrin homology $(\mathrm{PH})$ domain of the downstream target Akt/Protein Kinase $\mathrm{B}$ (PKB). The interaction of $\mathrm{PIP}_{3}$ with the $\mathrm{PH}$ domain enables phosphorylation of $\mathrm{Akt} / \mathrm{PKB}$ by phosphoinositide dependent kinase (PDK) 1 and PDK 2, ultimately triggering a number of metabolic actions, such as lipogenesis, glycogen synthesis, inhibition of hepatic glucose output and increased glucose uptake in muscle and adipose tissue.

Class IA PI3Ks consist of two subunits. The catalytic subunit, p110, contains the kinase domain responsible for the formation of $\mathrm{PIP}_{3}$. The regulatory subunit, the most common of which is $\mathrm{p} 85 \alpha$, binds to phosphorylated tyrosine residues in tyrosine kinases and their substrate proteins via its $\mathrm{SH} 2$ domain, leading to activation of PI3K activity. Both the regulatory and catalytic subunits exist as several different isoforms. In humans, there are four known catalytic subunit isoforms: $110 \alpha, \mathrm{p} 110 \beta, \mathrm{p} 110 \delta$ and $\mathrm{p} 37 \delta . \mathrm{p} 110 \alpha, \mathrm{p} 110 \beta$ and $\mathrm{p} 110 \delta$ are encoded by three different genes, $P I K 3 C A, P I K 3 C B$ and $P I K 3 C D$, respectively (reviewed in 1$)$, whereas p $37 \delta\left(P I K 3 C D \_v 2\right)$ is a splice variant of $\mathrm{p} 110 \delta^{3,4}$. We and others have shown that of these catalytic subunits, p1 $10 \alpha$ is the major contributor for transmitting the insulin signal ${ }^{5-7}$, whereas p $110 \beta$ becomes active primarily in response to $\mathrm{G}$ proteincoupled receptor signaling and plays a role in proliferation ${ }^{8,9} \cdot \mathrm{p} 110 \delta$ is more cell specific than $\mathrm{p} 110 \alpha$ and $\mathrm{p} 110 \beta$, and plays an important role in immune cells and the embryonic nervous system ${ }^{10-12}$.

The regulatory subunits are also encoded by three genes, PIK3R1, PIK3R2 and PIK3R3. Their primary gene products are p $85 \alpha, \mathrm{p} 85 \beta$ and $\mathrm{p} 55 \gamma$, respectively (reviewed in 1). PIK3R1 also encodes two splice variants of $\mathrm{p} 85 \alpha, \mathrm{p} 55 \alpha$ and $\mathrm{p} 50 \alpha$, which have more limited tissue distribution. $\mathrm{p} 85 \alpha$ is the major regulatory subunit isoform, constituting $65 \%-75 \%$ of the intracellular pool of regulatory subunits in most cells ${ }^{13}$. Despite the crucial role of the regulatory subunits of Class IA PI3K in mediating insulindependent PI3K signaling ${ }^{14,15}$, mice with a knockout $(\mathrm{KO})$ of the $\mathrm{p} 85 \alpha$ regulatory subunit display increased insulin sensitivity, increased levels of $\mathrm{PIP}_{3}$ lipids, elevated Akt/PKB activity and improved glucose tolerance ${ }^{13,16-19}$. The molecular mechanisms that underlie this negative regulation by $\mathrm{p} 85$ appear to be complex and include unbalanced stoichiometry between subunits ${ }^{20,21}$; effects of p85 on both protecting p110 from degradation while partially inhibiting its kinase activity ${ }^{16,19,21,22}$; retention of PI3K in an inactive vesicle compartment ${ }^{23}$; links between $\mathrm{p} 85 \alpha$ and PTEN activity $^{24}$; links between $\mathrm{p} 85 \alpha$ and JNK activity leading to IRS1 serine phosphorylation and inhibition of IRS1-mediated effects, and links between p $85 \alpha$ and XBP-1 in modifying the unfolded protein response ${ }^{25}$.

To dissect the intricate equilibrium between the catalytic and regulatory subunits of PI3K, as well as the opposing and complex roles of $\mathrm{p} 110 \alpha$ and $\mathrm{p} 85 \alpha$ in insulin signaling and action, in the present study, we have investigated the impact of a combined hepatic deletion of $\mathrm{p} 110 \alpha$ and $\mathrm{p} 85 \alpha$ on insulin signaling and whole body glucose homeostasis.

\section{Methods}

Animals

All mice in this study were on a $129 \mathrm{~Sv}-\mathrm{C} 57 \mathrm{Bl} / 6$ mixed genetic background. To create the liver double knock-out mice, p110 $\alpha$ loxlox mice ${ }^{7}$ were crossed with $\mathrm{p} 85 \alpha$ lox-lox mice, hemizygous for the Albumin-Cre recombinase transgene ${ }^{14}$. Mice were housed on a 12-hour light cycle and fed a standard rodent chow and water ad libitum. All protocols for animal use and euthanasia were approved by the Gothenburg Ethical Committee on Animal Experiments, in accordance with Swedish guidelines and Directive 2010/63/EU for animal experiments, and by the Animal Care Use Committee of the Joslin Diabetes Center and Harvard Medical School in accordance with National Institutes of Health guidelines. All efforts were made to ameliorate any suffering of the mice by reducing stress, hosting mice in small groups with items that stimulate their natural activity, and allowing the mice to recover 1-2 weeks after each procedure (such as measuring blood glucose, glucose tolerance test etc). During the insulin tolerance test, the mice were monitored closely to not fall too low in blood glucose levels.

For each experiment, a group of 5-12 male mice per genotype were used. The mice were studied from 6 weeks of age to 25 weeks of age. During this time weight and fasting blood glucose levels were measured every two weeks. Glucose tolerance test was performed at 8 weeks, 16 weeks and 24 weeks. Pyruvate tolerance test was performed at 15 weeks and insulin tolerance test was performed at 19 weeks.

\section{Metabolic and physiological procedures}

Animals were fasted overnight and anesthetized with 2-2-2 tribromoethanol (Sigma-Aldrich, St Louis MO), followed by injection of $5 \mathrm{U}$ of insulin (Actrapid, Novo Nordisk Inc., Plainsboro Township, NJ) or saline via the inferior vena cava. Five minutes after the injection, the liver, muscle and white adipose tissue (WAT) were excised, weighed, and snap-frozen in liquid nitrogen.

Glucose tolerance test was performed by intraperitoneal (i.p.) injection of $2 \mathrm{~g}$ glucose $/ \mathrm{kg} \mathrm{BW}$ after an overnight fast. Insulin tolerance test was performed by i.p. injection of $1.25 \mathrm{U}$ insulin $/ \mathrm{kg}$ BW. Pyruvate tolerance test was performed by i.p. injection of $2 \mathrm{~g}$ of pyruvate $/ \mathrm{kg} \mathrm{BW}$ after an over-night fast. Insulin was measured with ELISA (Crystal Chem Inc., Downer Grover, IL).

\section{RNA extraction and gene expression analysis}

RNA was extracted by homogenization of liver tissue in RLT buffer (Qiagen, Valencia, CA) followed by extraction using the RNeasy kit (Qiagen, Valencia, CA). For gene analysis, cDNA was prepared using a high capacity cDNA archive kit (Applied Biosystems, Foster City, CA) with random hexamer primers. Gene expression was analyzed by real-time reverse transcription-PCR (RT-PCR) on an ABI Prism sequence detection system (Applied Biosystems, Foster City, CA). The cycling conditions used were an initial $95^{\circ} \mathrm{C}$ 
10-minute step followed by 40 cycles of $95^{\circ} \mathrm{C}$ for $15 \mathrm{~s}$ and $60^{\circ} \mathrm{C}$ for 60 s. Samples were normalized to the $18 \mathrm{~S}$ rRNA gene. Primer sequences are available in Table 1.

\section{Protein extraction and analysis}

Liver tissue was homogenized in lysis buffer containing $25 \mathrm{mM}$ Tris- $\mathrm{HCl}, 2 \mathrm{mM} \mathrm{Na} \mathrm{VO}_{3}, 10 \mathrm{mM} \mathrm{Na}_{4} \mathrm{P}_{2} \mathrm{O}_{7}, 1 \mathrm{mM}$ EGTA, $1 \mathrm{mM}$ EDTA, 1\% NP-40 and protease inhibitors (Sigma-Aldrich, St Louis MO), then allowed to incubate at $4^{\circ} \mathrm{C}$ for one hour. Extracts were centrifuged at 55,000 rpm (Beckman 70.1 Ti rotor) for one hour, and the supernatant was stored at $-80^{\circ} \mathrm{C}$. WAT was homogenized in lysis buffer containing $25 \mathrm{mM}$ Tris- $\mathrm{HCl}, \mathrm{pH} 7.4,0.5 \mathrm{mM}$ EDTA, $25 \mathrm{mM} \mathrm{NaCl}, 1 \%$ Nonidet P-40, $10 \mathrm{mM} \mathrm{NaF}, 1 \mathrm{mM}$ orthovanadate, and protease inhibitors (Sigma-Aldrich, St Louis $\mathrm{MO})$ followed by incubation for $2 \mathrm{~h}$ at $4^{\circ} \mathrm{C}$. The samples were then centrifuged at $12,000 \mathrm{rpm}$ for $15 \mathrm{~min}$, and the supernatant was collected and stored at $-80^{\circ} \mathrm{C}$. Protein analysis was made by SDS-PAGE and subsequent western blot. Briefly, protein samples were loaded onto 4-12\% Bis-Tris protein gels (Thermo-Fisher Scientific, Waltham, MA) and subjected to gel electrophoresis using 25mM Tris, $192 \mathrm{mM}$ glycine and $0.1 \%$ SDS as running buffer. Samples were transferred onto a nitrocellulose membrane and the membranes were incubated in 5\% skim milk solution for $1 \mathrm{~h}$ followed by primary antibody incubation according to the manufacturer's protocol for each antibody. Membranes were washed $2 \times 5 \mathrm{~min}$ and $1 \times 15 \mathrm{~min}$ in PBS with $0.1 \%$ Tween and then incubated with the secondary antibody for $1 \mathrm{~h}$ followed by another washing procedure. Immunoprecipitation was performed using magnetic beads coated with protein G (Pierce Biotechnology Inc, Rockford, IL). All western blots and immunoprecipitation experiments were performed with a minimum of four replicates (four separate samples).

\section{Antibodies}

IRS1 (RRID:AB_2127860, rabbit monoclonal, 1:50, Cell Signaling Technology Inc, cat\# 3407 for western blot), IRS1 (RRID: AB_631842, rabbit polyclonal, 10 $\mu$ l per reaction, Santa Cruz Biotechnology Inc, cat\# sc-559 for immunoprecipitation), p110 $\alpha$ (rabbit monoclonal, 1:1000 for western blot and 1:50 for immunoprecipitation, Cell Signaling Technology Inc, cat\# 4249), p110ß (RRID:AB_2165246, rabbit monoclonal, 1:500 for western blot and 1:50 for immunoprecipitation, Cell Signaling Technol-

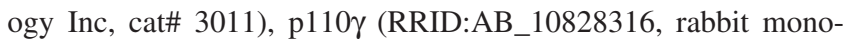
clonal, 1:1000, Cell Signaling Technology Inc, cat\# 5405), p110 (mouse monoclonal, 1:500, Becton, Dickinson and Company, cat\# 611015), p101 (RRID:AB_10829448, rabbit monoclonal, 1:1000, Cell Signaling Technology Inc, cat\# 5569), Vps34 (RRID:AB_ 2299765, rabbit monoclonal, 1:1000, Cell Signaling Technology Inc, cat\# 4263), p150 (rabbit polyclonal, 1:1000, Cell Signaling Technology Inc, cat\# 14580), Akt/PKB (RRID:AB_329827, rabbit polyclonal, 1:1000, Cell Signaling Technology Inc, cat\# 9272), pS-Akt/PKB (RRID:AB_329825, rabbit polyclonal, 1:1000, Cell Signaling Technology Inc, cat\# 9271), pT-Akt/PKB (RRID:AB_ 2255933, rabbit monoclonal, 1:1000, Cell Signaling Technology Inc, cat\# 2965), pT-p70S6K (RRID:AB_330944, rabbit polyclonal, 1:1000, Cell Signaling Technology Inc, cat\# 9205), p85 $\alpha$ (RRID: AB_2268174, rabbit monoclonal, 1:1000, Abcam, cat\# 22653), p85-pan (RRID:AB_10831521, rabbit monoclonal, 1:1000, Cell Signaling Technology Inc, cat\# 4257), pT202/Y204-ERK (RRID: AB_2315112, rabbit monoclonal, 1:1000, Cell Signaling Technology Inc, cat\# 4370), ERK (RRID:AB_390779, rabbit monoclonal, 1:1000, Cell Signaling Technology Inc, cat\# 4695), p55 $\gamma$ (mouse monoclonal, 1:2000, Abcam, cat\# ab186612), PIK3C2 $\alpha$ (rabbit polyclonal, 1:1000, MyBiosource, cat\# MBS9202698), PIK3C2 $\gamma$ (rabbit polyclonal, 1:1000, MyBiosource, cat\# MBS820611).

Table 1. Primer used for gene expression analysis.

\begin{tabular}{|l|l|l|l|}
\hline Gene & Type & Sequence/Assay ID\# & \\
\hline Pik3ca & Gene expression assay & Mm00435673_m1 & Thermo Fisher Scientific \\
\hline Pik3cb & Gene expression assay & Mm00659576_m1 & Thermo Fisher Scientific \\
\hline Pik3r1 & Gene expression assay & Mm01282781_m1 & Thermo Fisher Scientific \\
\hline Pik3r2 & Gene expression assay & Mm00435694_m1 & Thermo Fisher Scientific \\
\hline G6pc & Forward Primer & 5'-ACTGTGGGCATCAATCTCCT & \\
\hline G6pc & Reverse Primer & 5'-ACAGGTGACAGGGAACTGCT & \\
\hline G6pc & Probe & 5'-[6FAM]TGGGTGGCAGTGGTCGG & \\
\hline Pck1 & Forward Primer & 5'-TGGATGTCGGAAGAGGACTT & \\
\hline Pck1 & Reverse Primer & 5'-AGTGGCCCCATGCTGAAT & \\
\hline Pck1 & Probe & 5'-[6FAM]GTGCATGAAAGGCCGCA & \\
\hline Fbp1 & Forward Primer & 5'-AGCTGCTGAATTCCGCTCTG & \\
\hline Fbp1 & Reverse Primer & 5'-TTGATCACCAGGTCATTGGA & \\
\hline Fbp1 & Probe & 5'-[6FAM]GCGGGCATCGCACAGCT & \\
\hline 18S & Gene expression assay & 4310893E \\
\hline
\end{tabular}


Rabbit secondary antibody (RRID:AB_772206, HRP-linked from donkey, 1:1000, GE Healthcare Life Sciences, cat\# NA934), mouse secondary antibody (RRID:AB_772210, HRP-linked from sheep, 1:1000, GE Healthcare Life Sciences, cat\# NA931).

\section{In vitro kinase assays}

Immunoprecipitates, using protein $G$ Dynabeads (Life Technologies), of liver protein lysates were prepared with p110 $\alpha$ and p110 $\beta$ antibodies or IRS1 antibody. The PI3K assay was performed as previously described ${ }^{13}$. Briefly, immunoprecipitates were incubated with $5 \mu \mathrm{g}$ PI substrate (phosphatidylinositol from bovine liver), $20 \mathrm{mM} \mathrm{MgCl}, 8 \mu \mathrm{M}$ cold ATP and $0.5 \mu \mathrm{l}$ radio-labeled $\left[\gamma^{32} \mathrm{P}\right]$-ATP $\left(1.11^{*} 10^{14} \mathrm{bq} / \mathrm{mmol}\right)$ in PI3K reaction buffer ( $20 \mathrm{mM}$ Tris-HCl, $100 \mathrm{mM} \mathrm{NaCl}$ and $0.5 \mathrm{mM}$ EGTA) for $25 \mathrm{~min}$ at room temperature. The resulting radioactively labeled PIP was analyzed with thin layer chromatography and phosphorimaging (FLA-3000, Fujifilm). Prior to these experiments, titration experiments of bead concentration and PI substrate concentration were performed to ensure precipitation of equal amounts of protein, as well as optimal PI concentration to obtain maximal enzyme activity.

\section{Statistics}

All data are presented as mean \pm standard error of the mean (SEM). Student's t-test was used for statistical analysis between two unpaired groups. A p-value of $<0.05$ was considered statistically significant. The statistical software used was GraphPad Prism 7.00.

\section{Results \\ Deletion of hepatic $p 110 \alpha$ and $p 85 \alpha$ results in impaired insulin signaling downstream of PI3K}

Mice with a liver-specific deletion of $\mathrm{p} 110 \alpha$ and $\mathrm{p} 85 \alpha$, termed hereafter liver double knockout (L-DKO) mice, were created by breeding mice carrying homozygous floxed Pik3ca and Pik3rl alleles $^{14,26}$ with transgenic mice carrying the Cre recombinase driven by the albumin promoter (albumin-Cre). Deletion of Pik3ca and Pik3rl in the liver resulted in markedly reduced gene and protein expression of $\mathrm{p} 110 \alpha$ and $\mathrm{p} 85 \alpha$ (Figures 1A, $1 \mathrm{C}, 1 \mathrm{E})$, as well as impaired activation of the downstream targets $\mathrm{Akt} / \mathrm{PKB}$, with decreased phosphorylation of serine 473 and threonine 308, and p70S6 kinase (Figure 1F). p110 3 gene expression was not affected by the deletion of $\mathrm{p} 110 \alpha$ and $\mathrm{p} 85 \alpha$ (Figure 1B). p $85 \beta$ gene expression was slightly, but significantly, decreased in the L-DKO livers (Figure 1D). As expected, in the floxed control mice, there was an increase in the amount of $\mathrm{p} 110 \alpha$ associated with IRS1 in response to insulin compared to basal conditions, whereas no $110 \alpha$ was associated with IRS1 in the L-DKO mice (Figure 1G). MAPK signaling, as shown by ERK phosphorylation, was unchanged in the L-DKO mice compared to controls (Figure 1F).

Previous studies have shown that the interaction between the regulatory and catalytic subunits of PI $3 \mathrm{~K}$ to form dimers has a mutual stabilizing effect on both subunits, whereas the monomeric forms are more readily subjected to degradation ${ }^{19,21,22}$. We hypothesized that more $\mathrm{p} 85 \beta$ would bind to IRS 1 when $\mathrm{p} 85 \alpha$ was absent, thereby maintaining p110 $\beta$ stabilization. However, only very low levels of $\mathrm{p} 85 \beta$ protein were detected in the liver of the L-DKO mice, as shown both in assessment of total p85 protein (Figure 1E) and in p85 immunoprecipitates with IRS1 (Figure 1G). The expression of $\mathrm{p} 55 \gamma$ regulatory isoform protein was not affected by deletion of $\mathrm{p} 110 \alpha$ and $\mathrm{p} 85 \alpha$ (Figure $1 \mathrm{E}$ ), nor was the amount bound to IRS1 (Figure 1G). In contrast, total p110 $\beta$ protein expression was decreased in the L-DKO mice compared to controls (Figure 1E), likely due to destabilization of this catalytic isoform in the absence of $\mathrm{p} 85 \alpha$, supporting an insufficiency for $\mathrm{p} 85 \beta$ to compensate for the loss of $\mathrm{p} 85 \alpha$. Interestingly, despite overall decreased protein expression of $\mathrm{p} 110 \beta$, similar amounts of p110 $\beta$ were associated with IRS1 in controls and L-DKO mice (Figure $1 \mathrm{G}$ ). The third catalytic isoform of class IA PI3Ks, p110 $\delta$, has been shown to have a major role in immune cells and the embryonic nervous system, but not in other tissues ${ }^{10-12}$. Consistent with this, we found only very small amounts of full length p $110 \delta$ in whole liver lysates or bound to IRS1 (Figure 1G). However, the antibody picked up a band of about $70 \mathrm{kDa}$ in whole lysates and in IRS1 immunoprecipitates (Figure 1G). The amount of this protein did not appear to be consistently different between controls and L-DKO mice or between basal and insulin-stimulated samples, so is likely non-specific.

IRS1-associated phosphatidylinositol kinase activity is intact in the L-DKO mice

As expected, p110 $\alpha$ kinase activity, as assessed by the ability to add the 3'-phosphate group to phosphoinositides in p110 $\alpha$ immunoprecipitates, was markedly decreased both in the basal- and insulin-stimulated states of the L-DKO mice compared to controls (Figure 2A). Overall p110 $\beta$ kinase activity was much lower than p $110 \alpha$ kinase activity in control mice, consistent with previous studies $^{7,27}$, and was not changed in the basal state between controls and L-DKO mice (Figure 2B). However, p110 $\beta$ kinase activity was significantly decreased in the insulin-stimulated state of the L-DKO mice (Figure 2B), even though similar amounts of p110 $\beta$ protein were associated with IRS1 in controls and L-DKO mice (Figure 1G). Surprisingly, IRS1-associated phosphatidylinositol kinase activity in response to insulin was intact in the L-DKO, despite lack of $\mathrm{p} 110 \alpha$ kinase activity and decreased $\mathrm{p} 110 \beta$ activity (Figure 2C).

The intact IRS1-associated kinase activity in the L-DKO mice cannot be explained by compensatory upregulation of other classes of PI3K

To explore if other classes of phosphoinositide 3-kinases were responsible for the intact IRS1-associated activity, we investigated the association of IRS1 with class IB-, class II and class III members of phosphoinositide 3-kinases in liver lysates from controls and L-DKO mice. Class IB PI3K consists of the p110 $\gamma$ catalytic subunit and the p101 regulatory subunit. The amount of p101 was low in whole lysates and no p101 was associated with IRS1 in either control mice or L-DKO mice (Figure 2D). p110 $\gamma$ was associated with IRS1, but the amounts were similar between controls and L-DKO mice (Figure 2D). Class III PI3K catalytic subunit Vps34 and regulatory subunit p150 were present in whole lysates, but not associated with IRS1 in either control mice or L-DKO mice (Figure 2D). Class II PI3K consists of only one subunit, but exists in several isoforms. The PI3K-C2 $\alpha$ isoform is ubiquitously 
A

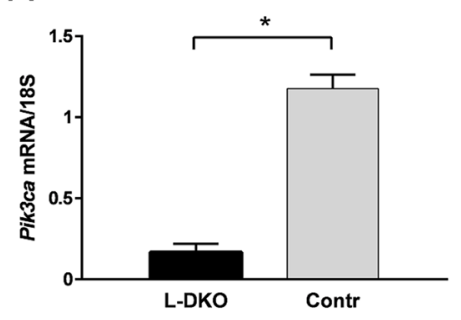

C

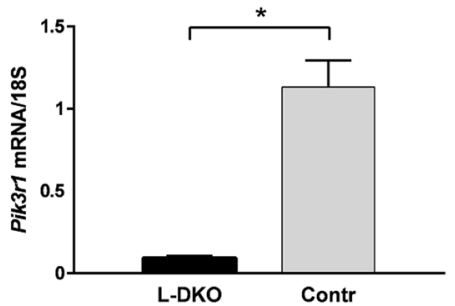

$E$
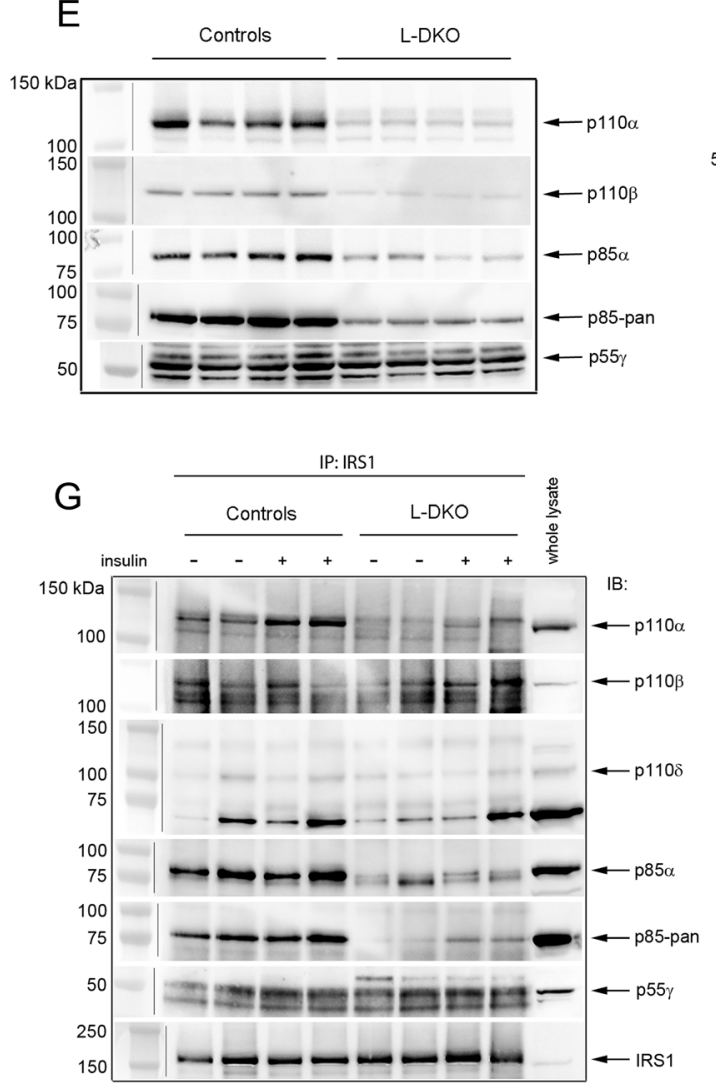

B

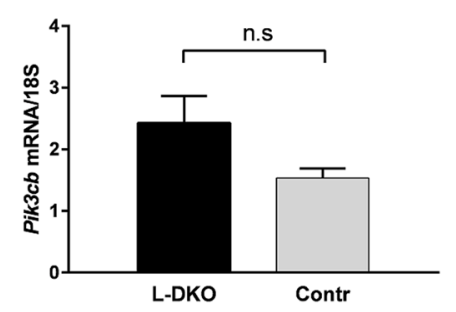

D
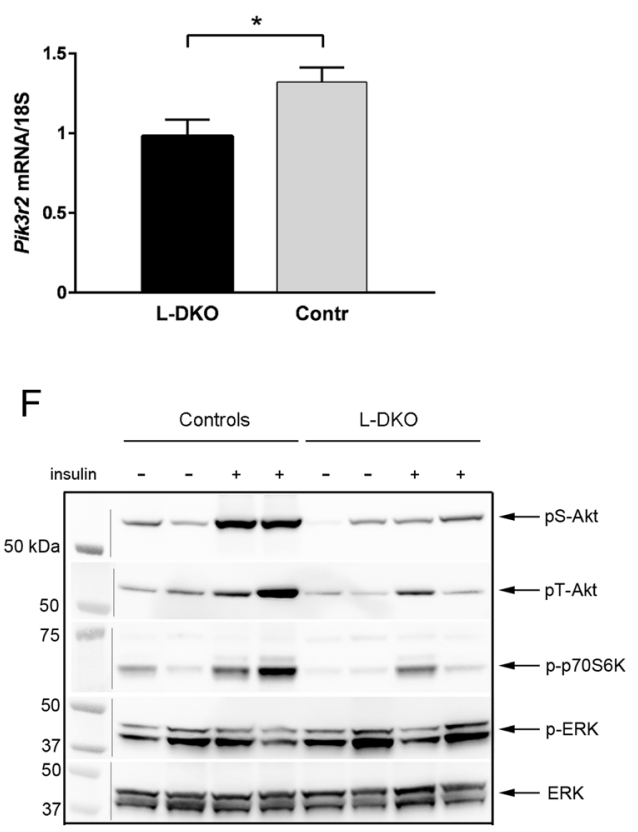

Figure 1. Gene- and protein-expression of regulatory and catalytic subunits of PI3K and associated insulin signaling mediators. mRNA expression of (A) Pik3ca, (B) Pik3cb, (C) Pik3r1 and (D) Pik3r2 in livers of flox controls and L-DKO mice. (E) Representative western blot of protein expression of p110 $\alpha$, p110 $\beta$, p85 $\alpha$, p85-pan (detects both p85 isoforms) and p55 $\gamma$ and (F, phosphorylated Akt/PKB (Ser 473 and Thr 308), phosphorylated p70S6 kinase, and phosphorylated ERK in livers of flox controls and L-DKO mice. Total ERK was used as a loading control. (G) Representative western blot of immunoprecipitation experiments with antibodies for IRS1 and subsequent immunoblotting with antibodies for $\mathrm{p} 110 \alpha, \mathrm{p} 110 \beta, \mathrm{p} 110 \delta$, p $85 \alpha$, p85-pan (detects both $\mathrm{p} 85$ isoforms) and p55 $\gamma$. The whole-lysate reference sample was from an insulin-treated flox control mouse. IP = immunoprecipitation, IB = immunoblot. Basal condition is indicated with a minus (-) sign, insulin-treated condition is indicated with a plus (+) sign. Basal conditions refer to fasting of mice overnight. Insulin treatment refers to injection of $5 \mathrm{U}$ of insulin through the vena cava 5 min prior to euthanization. Error bars indicate SEM $(n=5-8)$. *,$p<0.05$ compared to controls. n.s $=$ non significant. Images containing a vertical line are composites taken from a single original image. 
A
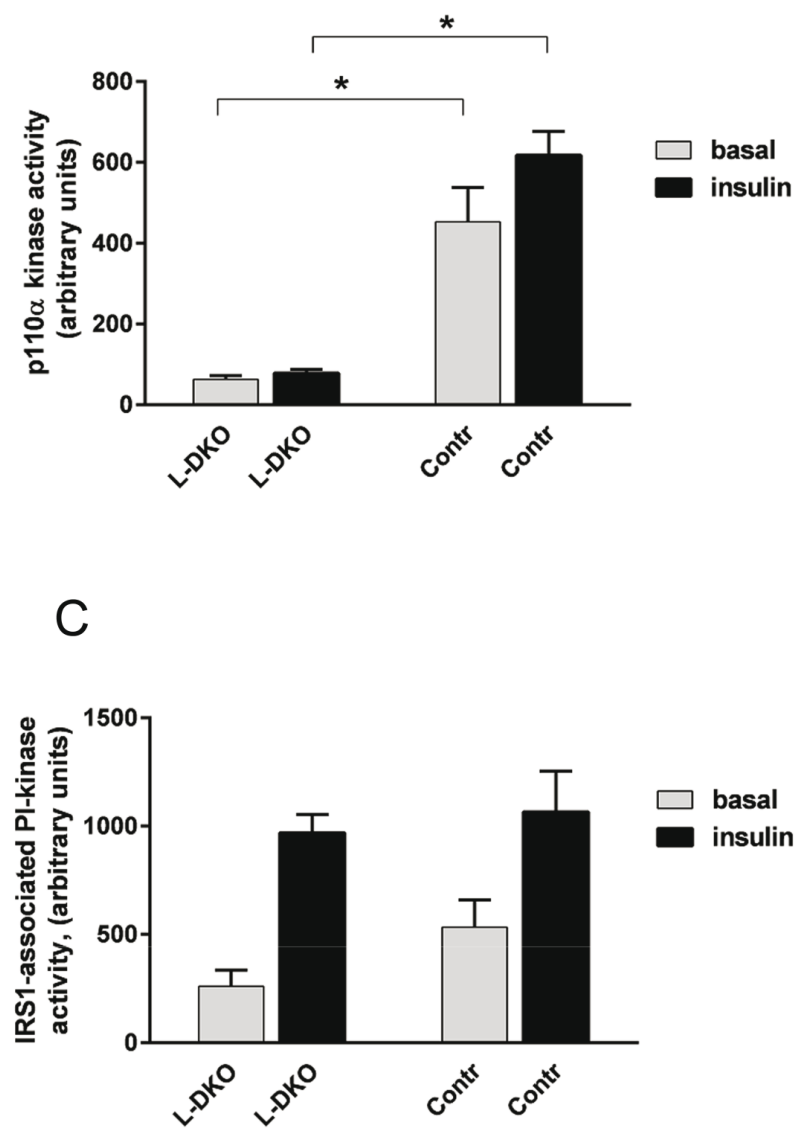

B

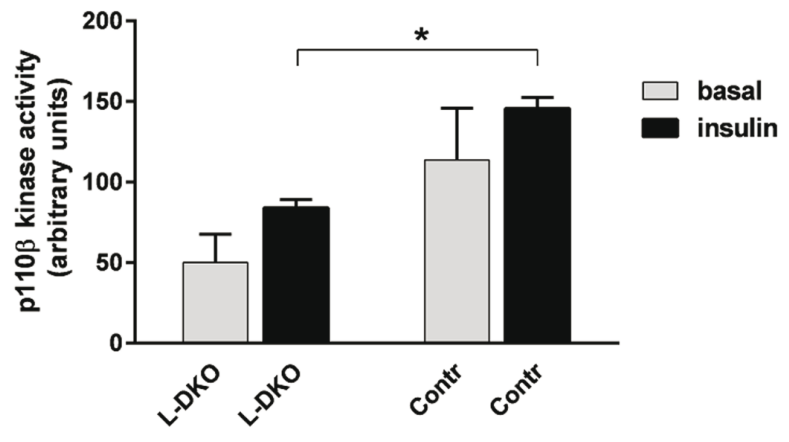

D

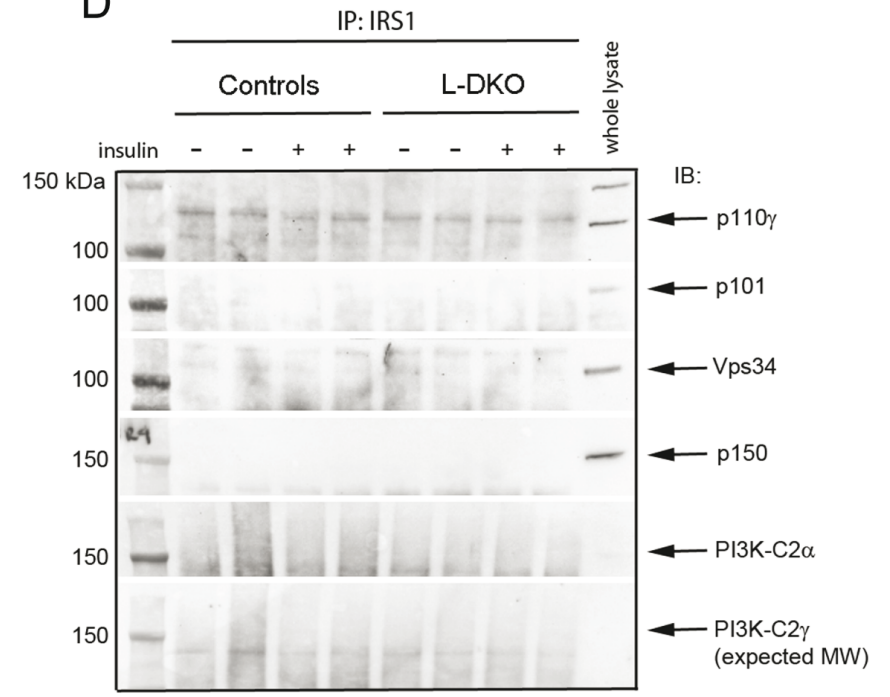

Figure 2. PI3K activity and assessment of the association of IRS1 with class IB-, class II- and class III-members of phosphoinositide 3-kinases. (A) p110 $\alpha$ lipid kinase activity, (B) p110ß lipid kinase activity, and (C) IRS1-associated phosphatidylinositol (PI) kinase activity in L-DKO mice and controls were assessed by immunoprecipitation. (D) Representative western blot of immunoprecipitation experiments with antibodies for IRS1 and subsequent immunoblotting with antibodies for p110 $\gamma$, p101, Vps34, p150, PIK3-C2 $\alpha$ and PIK3-C2 $\gamma$. The whole-lysate reference sample was from an insulin-treated flox control mouse. IP = immunoprecipitation, IB = immunoblot. Basal condition is indicated with a minus (-) sign, insulin-treated condition is indicated with a plus (+) sign. Basal conditions refer to fasting of mice overnight. Insulin treatment refers to injection of $5 \mathrm{U}$ of insulin through the vena cava 5 min prior to euthanization. Error bars indicate SEM $(n=4)$. ${ }^{*}, p<0.05$ compared to controls.

expressed, whereas $\mathrm{PI} 3 \mathrm{~K}-\mathrm{C} 2 \gamma$ has been reported to have a more limited tissue distribution, including hepatocytes ${ }^{28,29}$. However, we detected only little or no PI3K-C $2 \alpha$ or PI3K-C $2 \gamma$ in whole liver lysates or associated with IRS1 in controls or L-DKO mice (Figure 2D). Thus, other classes of phosphoinositide 3-kinases did not compensate for the loss of $\mathrm{p} 110 \alpha$ and $\mathrm{p} 85 \alpha$ in the L-DKO mice and could not explain the intact IRS1-associated phosphatidylinositol kinase activity in the absence of $\mathrm{p} 110 \alpha$ and $\mathrm{p} 85 \alpha$.

\section{L-DKO mice have decreased liver weight and WAT weight compared to controls}

On standard chow ( $4 \%$ fat content by weight, $12 \%$ by calories), L-DKO mice had similar body weights to the flox control mice until 10-12 weeks of age, after which the L-DKO mice showed slower weight gain compared to controls (Figure 3A). At least part of this decrease was due to a decrease in liver weight. Thus, by 10 weeks of age, the ratio of liver weight to body weight in the L-DKO mice was decreased by $13 \%$ compared to control mice (Figure 3B), whereas there was no difference in WAT weight or muscle weight (Figures 3C and 3D). At 24 weeks of age, liver weight remained decreased (18\%), and there was also a significant decreased WAT weight $(22 \%)$ for the L-DKO mice compared to controls (Figures $3 \mathrm{~B}$ and $3 \mathrm{C}$ ). To assess a possible change in insulin sensitivity in WAT, associated with the decreased WAT mass, we investigated insulin signaling mediators in this tissue. WAT p $110 \alpha$ - and p $85 \alpha$ expression was similar in controls and L-DKO mice as was Akt/PKB phosphorylation in response to insulin (Figure 3E). There was no difference in insulin-stimulated $\mathrm{Akt} / \mathrm{PKB}$-activation at $10 \mathrm{w}$ compared to $25 \mathrm{w}$ in either controls or L-DKO mice (Figure 3E). 
A

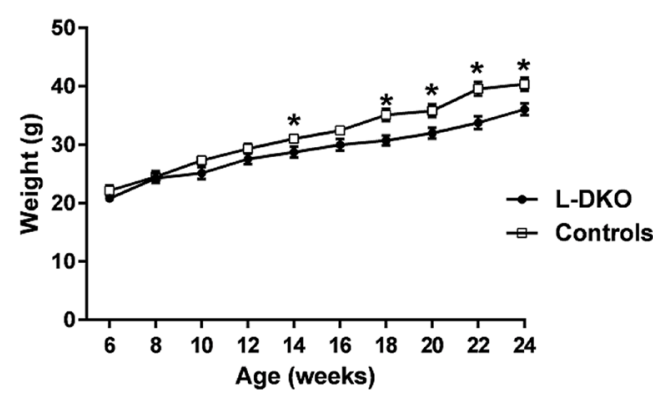

C

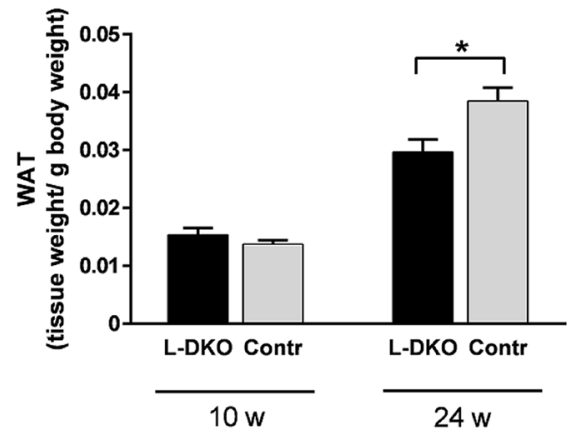

B

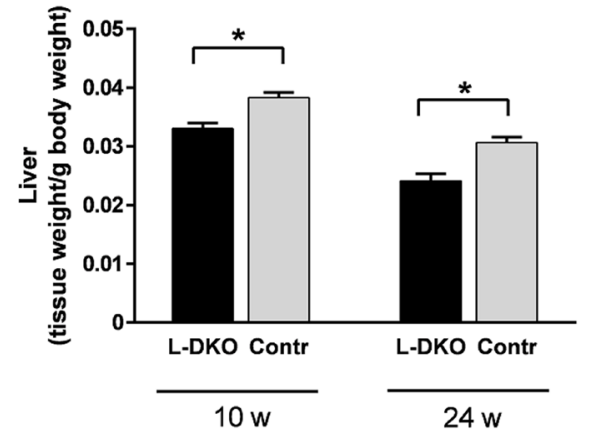

D

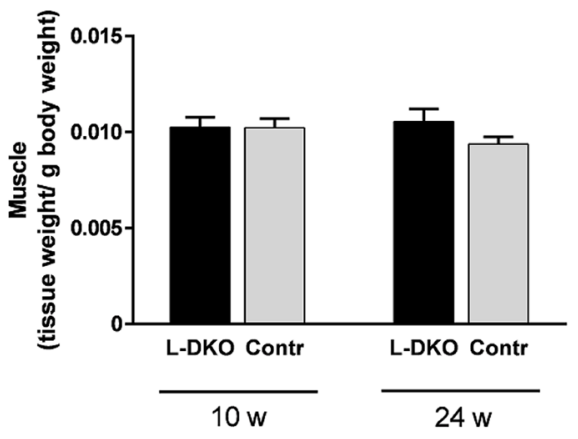

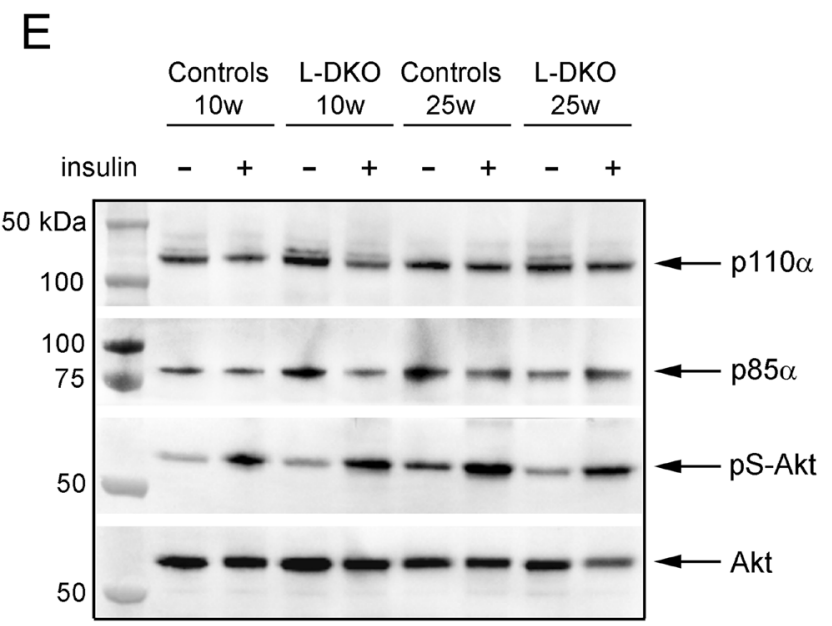

Figure 3. Body weight, tissue weights and adipose insulin signaling. (A) whole body weight, (B) liver weight, (C) white adipose tissue (WAT) weight and (D) muscle weight of 10 and 24 week old male L-DKO mice and controls. (E) Representative western blot of p110 $\alpha$, p85 $\alpha$ and phosphorylated Akt/PKB (Ser 473) in WAT of 10 and 25 week old male flox controls and L-DKO mice. Total Akt/PKB was used as a loading control. Basal condition is indicated with a minus (-) sign, insulin-treated condition is indicated with a plus $(+)$ sign. Basal conditions refer to fasting of mice overnight. Insulin treatment refers to injection of $5 \mathrm{U}$ of insulin through the vena cava 5 min prior to euthanization. Error bars indicate SEM $(n=8-17)$. ${ }^{\star}, p<0.05$ compared to controls. $w=$ weeks.

L-DKO mice have impaired glucose tolerance, but normal insulin tolerance and normal blood glucose levels

Despite similar body weight (Figure 3A), L-DKO mice were severely glucose intolerant as early as at 8 weeks of age (Figure 4A), and remained similarly glucose intolerant throughout the 24 week study (Figures 4B and 4C). This was associated with markedly increased fasting insulin levels (Figure 4D). However, somewhat surprisingly, the L-DKO mice showed a normal response to exogenous insulin during an intraperitoneal insulin tolerance test (Figure 4E). Despite the markedly impaired 

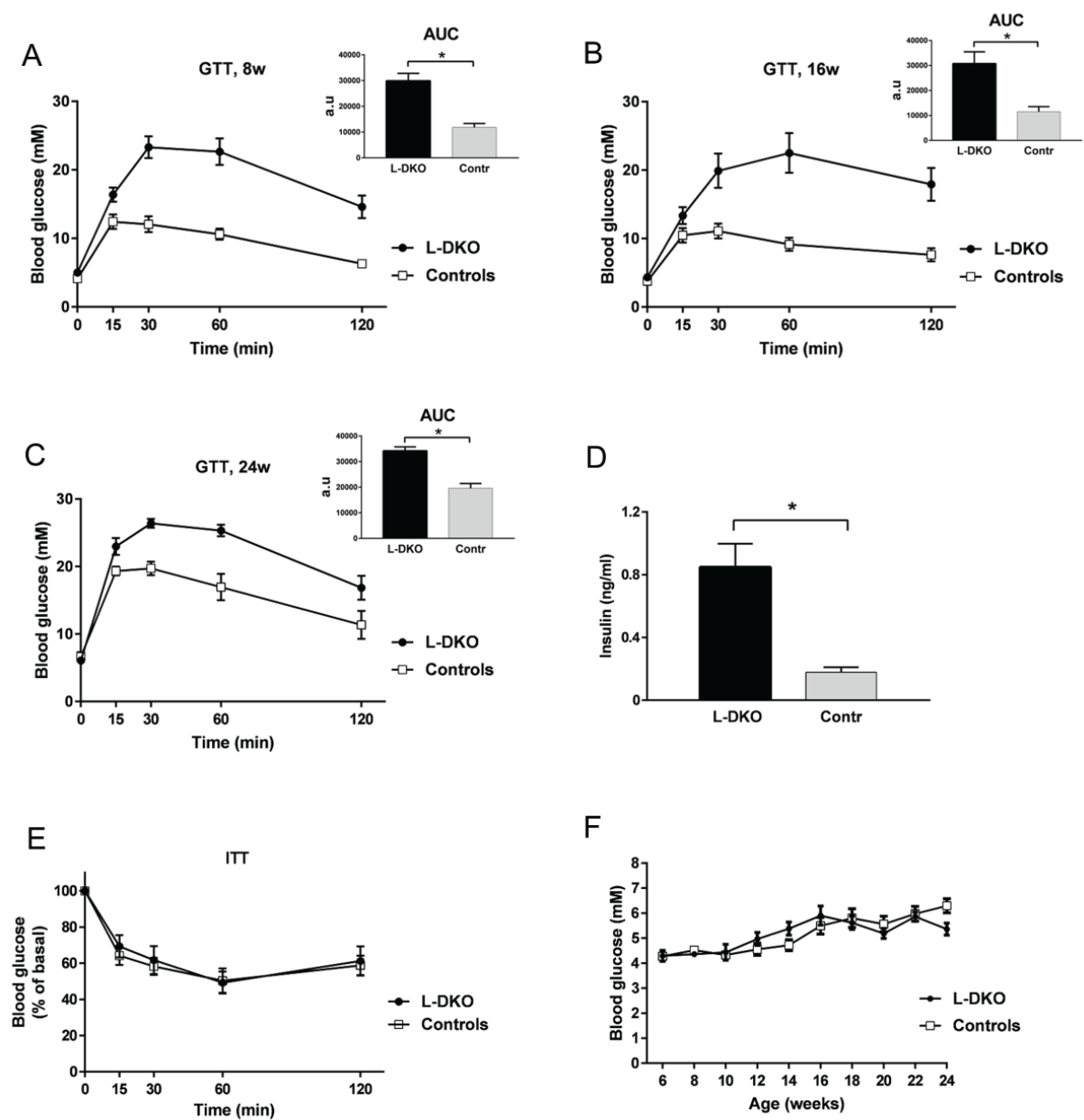

$\mathrm{F}$

G

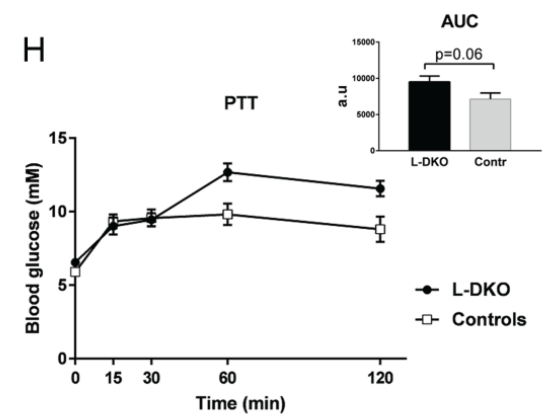

I
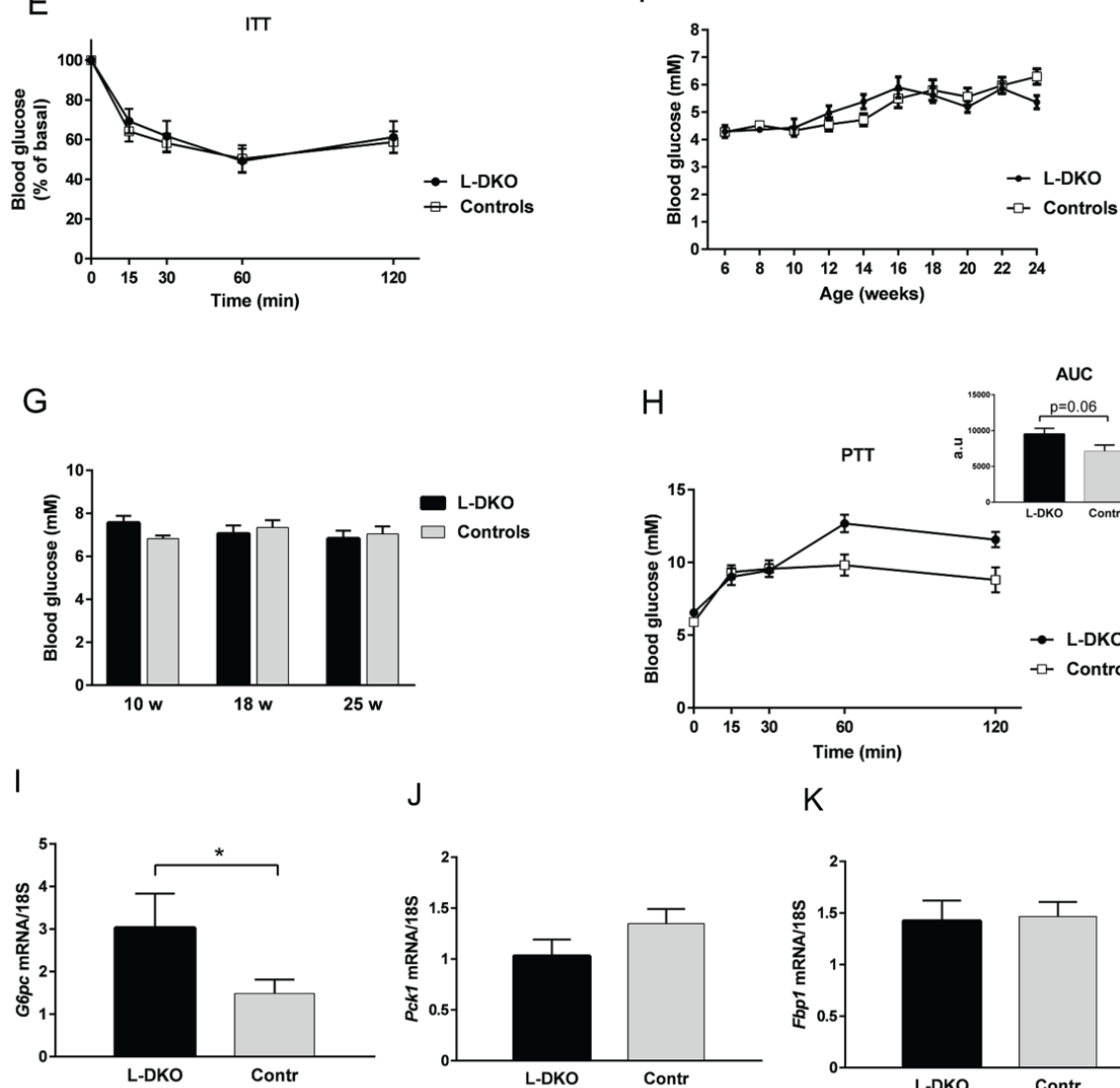

$\mathrm{J}$

$\mathrm{K}$
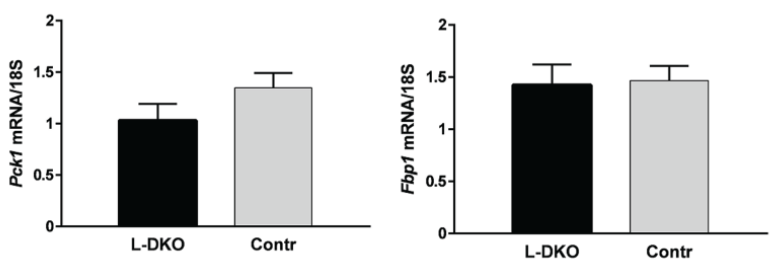

Figure 4. Glucose homeostasis. Glucose tolerance test at (A) 8 weeks, (B) 16 weeks and (C) 24 weeks of age; (D) fasting insulin levels at 10 weeks of age; $(\mathbf{E})$ insulin tolerance test at 19 weeks of age; $(\mathbf{F})$ fasting glucose levels; $(\mathbf{G})$ random fed glucose levels; (H) pyruvate tolerance test at 15 weeks of age; (I-K) hepatic mRNA expression of the gluconeogenic markers glucose 6-phosphatase (G6pc), phosphoenolpyruvate carboxykinase (Pck1) or fructose 1,6-bisphosphatase (Fbp1). L-DKO mice and controls were given $2 \mathrm{~g}$ glucose/kg body weight intraperitoneally (i.p.) for the glucose tolerance test or $1.25 \mathrm{U}$ insulin/kg body weight i.p. for the insulin tolerance test or 2 g pyruvate/kg body weight i.p. for the pyruvate tolerance test. Blood glucose was measured at 0, 15, 30, 60, and 120 min. Error bars indicate SEM $(n=6-12) .{ }^{*}, p<0.05$. The insets in the glucose tolerance test graphs and the pyruvate tolerance test graph show the area under the curve (AUC) with subtracted basal glucose values. 
glucose tolerance and marked hyperinsulinemia, fasting and random fed glucose levels in the L-DKO mice remained similar between controls and L-DKO mice (Figures 4F and 4G).

\section{L-DKO mice display normal hepatic glucose production}

Increased gluconeogenesis is one of the hallmarks of hepatic insulin resistance in type 2 diabetes. To determine whether the impaired glucose tolerance in L-DKO mice was due to increased hepatic glucose output, we subjected these animals to a challenge with pyruvate, the major gluconeogenic substrate. Over the 120 min period following administration of pyruvate, there was a trend toward increased glucose levels in L-DKO mice compared to controls, but this was not statistically significant (Figure 4H). This was associated with a significant change in hepatic gene expression of the gluconeogenic enzyme glucose 6-phosphatase $(G 6 p c)$ (Figure 4I), whereas gene expression of the other key mediators of gluconeogenesis, phosphoenolpyruvate carboxykinase $(P c k 1)$ and fructose 1,6-bisphosphatase ( $F b p l)$, remained similar between control mice and L-DKO mice (Figures 4J and $4 \mathrm{~K})$.

\section{Dataset 1. Raw data for gene and protein expression shown in Figure 1}

http://dx.doi.org/10.5256/f1000research.12418.d175493

\section{Dataset 2. Raw data for PI3K activity measurements and protein} expression shown in Figure 2

http://dx.doi.org/10.5256/f1000research.12418.d175494

Dataset 3. Raw data for body and tissue weights and protein expression shown in Figure 3

http://dx.doi.org/10.5256/f1000research.12418.d175495

Dataset 4. Raw data for metabolic procedures and measurements and gene expression shown in Figure 4

http://dx.doi.org/10.5256/f1000research.12418.d175496

\section{Discussion}

In this study, we investigated the impact of a combined deletion of $p 110 \alpha$ and $p 85 \alpha$ on insulin signaling and glucose homeostasis. For this purpose, we created mice with a liver-specific deletion of the major catalytic and major regulatory subunits of PI3K: Pik3ca and Pik3rl. We have previously shown that hepatic deletion of only $\mathrm{p} 110 \alpha$ results in severe insulin resistance and impaired glucose tolerance, signifying that $\mathrm{p} 110 \alpha$ is crucial for mediating insulin signaling 7 . Moreover, mice deficient in all p85 isoforms in either muscle or liver exhibit severely impaired insulin signaling in these tissues ${ }^{14,15}$. The liver plays a crucial role in maintaining glucose homeostasis; we therefore hypothesized that deleting both these isoforms would result in severe and overt diabetes.
As expected, in the L-DKO mice, $\mathrm{p} 110 \alpha$ catalytic activity was blunted and, as a result, the activation of the signal downstream of PI3K was markedly decreased. However, the L-DKO mice showed normal fasting and fed blood glucose levels throughout the study (24 weeks) and normal insulin tolerance. Glucose tolerance was impaired in the L-DKO mice and circulating insulin levels were markedly elevated, but to a degree similar to mice with only p $110 \alpha$ deleted in the liver $(\mathrm{L}-\mathrm{p} 110 \alpha \mathrm{KO})^{7}$. Surprisingly, despite abolished $\mathrm{p} 110 \alpha$ activity, we observed an intact total IRS1-associated phosphatidylinositol (PI) kinase activity in the L-DKO mice. This finding was very different from what we previously observed in L-p1 $10 \alpha$ KO mice, which only have $\mathrm{p} 110 \alpha$ deleted in the liver? In the L-p110 $\alpha$ KO mice, insulin-stimulated IRS1-associated PI kinase activity was markedly blunted ${ }^{7}$. This suggests that it is the loss of the regulatory subunit that accounted for the preserved IRS1-associated activation, possibly by enabling other phosphatidylinositol kinases to bind to IRS1. However, there did not appear to be any compensatory effects of other known catalytic and regulatory class IA subunit isoforms for the action of insulin. Thus, we did not detect any differences in the IRS1-associated amounts of $\mathrm{p} 110 \beta, \mathrm{p} 110 \delta$ or $\mathrm{p} 55 \gamma$ in controls and L-DKO mice in response to insulin and only very small amounts of $p 85 \beta$ associated with IRS1 in the L-DKO mice. Similarly, no evidence of compensatory effects by class IB, class II or class III members of phosphoinositide 3-kinases were found.

Previous studies by us and others, including our study of the L-p1 $10 \alpha$ KO mice, have shown that p110 $\beta$ is unable to compensate for the loss of $\mathrm{p} 110 \alpha^{7,26,30}$. However, we observed similar amounts of IRS1-associated p110 $\beta$ in the L-DKO mice and controls despite overall total decreased levels of p110 $\beta$ in the liver. We therefore speculated that perhaps p $110 \beta$ activity was increased in response to insulin in the L-DKO mice compared to controls, which would explain the sustained IRS1-associated PI kinase activity. We found no difference in the p110 $\beta$ activity between the controls and the L-DKO mice in the basal state. In addition, the p110 $\beta$ kinase activity was significantly decreased, rather than increased, in the insulin-stimulated state of L-DKO mice. We thus conclude that the sustained IRS1-associated PI kinase activity in the L-DKO mice is not due to increased activity of $\mathrm{p} 110 \beta$.

Although the amount of IRS1-associated p110 $\beta$ was similar in controls and L-DKO, the total amount of $\mathrm{p} 110 \beta$ was decreased in the L-DKO mice. We, and others, have previously reported that the dimeric interaction between the regulatory and the catalytic subunits results in stabilization of the subunits, whereas the monomeric forms are more readily subjected to degradation ${ }^{18,20-21}$. Therefore, the absence of the major regulatory subunit p85 $\alpha$ in the L-DKO mice probably subjects $\mathrm{p} 110 \beta$ to more rapid degradation. In this context, observing similar amounts of p110 $\beta$ associated with IRS1 in controls and L-DKO mice is somewhat surprising, but is likely due to stabilization of a fraction of p110 $\beta$ subunits by interaction with IRS1-associated $\mathrm{p} 85 \beta$ or $\mathrm{p} 55 \gamma$.

Lack of the major regulatory subunit in the L-DKO mice, accompanied by absence of increased activation of $\mathrm{p} 110 \beta$ or compensatory 
increased expression of other phosphoinositide 3-kinases, suggests that presence of other classes of phosphatidylinositol kinases, perhaps PI4K and PI5K, account for the intact IRS1-associated kinase activity by directly binding to IRS1. PI4Ks have been described as mediators of endosomal trafficking from the Golgi and to be involved in EGF-stimulated phosphoinositide signaling ${ }^{31}$. Type II PI4Ks interact with the EGF receptor, but they are not known to interact with IRS1. Type III PI4Ks are structurally related to PI3Ks, with a high degree of conservation between their catalytic domains and sensitivity to wortmannin ${ }^{31}$. The isoform PI4KIII $\alpha$ has been reported to be functionally connected to PI3K in FGF signaling during pectoral fin development in the zebra fish ${ }^{32}$.

PI5K exists as two separate classes, PI(3)P5K and PI(4)P5K, phosphorylating the D5 position of the inositol ring of phosphatidylinositol 3-phosphate and phosphatidylinositol 4-phosphate, respectively. Of the $\mathrm{PI}(4) \mathrm{P} 5 \mathrm{Ks}$, the isozyme PIP5Kc has been shown to respond to, and become phosphorylated by, various hormones and growth factors, such as EGF, and play a role in actin cytoskeletal reorganization, clathrin-dependent endocytosis, membrane ruffle formation, etc. ${ }^{33}$. However, a direct effect on insulin signaling and interaction with IRSs by PIP5Kc has not been reported. PI(3)P5K, also called PIKfyve, and has been quite extensively studied and reported to be involved in membrane trafficking, stress- or hormone-induced signaling, ion channel activity, cytoskeletal dynamics, nuclear transport, gene transcription and cell cycle progression ${ }^{34}$. Interestingly, PIKfyve is regulated by insulin, recruiting PIKfyve to inner membranes, where insulin receptor and IRSs are also found ${ }^{35}$, and co-precipitates with p110 and p85 subunits in 3T3-L1 adipocytes ${ }^{36}$. Thus, PIKfyve appears to be a possible contributor to the sustained IRS1-associated kinase activity in the L-DKO mice. However, PIKfyve expression has been reported to be rather tissue specific, mainly expressed in adipose tissue, muscle and brain ${ }^{37,38}$ and expression in the liver appears low $^{37,38}$. A more extensive follow-up investigation of the various phosphoinositides in the L-DKO livers compared to controls may help elucidating the phosphatidylinositol kinase responsible for the sustained IRS1-associated kinase activity in the L-DKO mice.

The absence of both $\mathrm{p} 85 \alpha$ and $\mathrm{p} 110 \alpha$, as seen in the L-DKO mice, would logically result in a very severely impaired metabolic phenotype. The L-DKO mice had markedly elevated circulating insulin levels, impaired glucose tolerance and showed a trend toward increased rates of hepatic glucose output when given pyruvate. However, fasted and fed glucose levels were not different between controls and L-DKO mice, i.e., randomly fed L-DKO mice were not diabetic and insulin tolerance tests were normal. Part of this protection might be the fact that L-DKO mice had less accumulation of WAT with age. In addition, it is possible that the high circulating insulin levels reflect an impaired hepatic insulin clearance rather than insulin resistance in the muscle, which would explain the paradoxical normal insulin tolerance. Interestingly, body weight, WAT weight and hepatic glucose output were significantly increased and insulin tolerance severely impaired in L-p110 $\alpha \mathrm{KO}$ mice ${ }^{7}$, which lack only p110 $\alpha$ in liver, demonstrating that L-DKO mice showed an overall less severe metabolic phenotype compared to L-p110 $\alpha$ KO mice.

In summary, deletion of hepatic $\mathrm{p} 110 \alpha$ and $\mathrm{p} 85 \alpha$ results in an impaired insulin signal and impaired glucose homeostasis, but shows an overall less severe metabolic phenotype compared to mice with only p $110 \alpha$ deleted in the liver. Although other PI3Ks were unable to compensate for the loss of p110 $\alpha$ and p $85 \alpha$, IRS1associated phosphatidylinositol kinase activity was surprisingly still intact, possibly due to interaction of IRS1 with other classes of phosphatidylinositol kinases.

Abbreviations: Fbp, fructose-1,6-bisphosphatase; G6pc, glucose6-phosphatase; GTT, glucose tolerance test; ITT, insulin tolerance test; L-DKO, liver double knockout; Pck, phosphoenolpyruvate carboxykinase; PI3K, phosphatidylinositol-4,5-bisphosphate 3-kinase; PKB, protein kinase B; PTT, pyruvate tolerance test; WAT, white adipose tissue

\section{Data availability}

Dataset 1: Raw data for gene and protein expression shown in Figure 1. DOI, 10.5256/f1000research.12418.d175493 $3^{39}$

Dataset 2: Raw data for PI3K activity measurements and protein expression shown in Figure 2. DOI, 10.5256/f1000research.12418. d $175494^{40}$

Dataset 3: Raw data for body and tissue weights and protein expression shown in Figure 3. DOI, 10.5256/f1000research.12418. d $175495^{41}$

Dataset 4: Raw data for metabolic procedures and measurements and gene expression shown in Figure 4. DOI, 10.5256/ f1000research.12418.d175496 ${ }^{42}$

\section{Competing interests}

No competing interests were disclosed.

\section{Grant information}

This work was supported by the Swedish Research Council (VRS), the Sahlgrenska Academy Foundation (VRS), the Magnus Bergvall foundation (VRS), and the Wilhelm and Martina Lundgren Foundation (VRS). The work was also supported by NIH grant DK055545 (CRK).

The funders had no role in study design, data collection and analysis, decision to publish, or preparation of the manuscript. 
1. Engelman JA, Luo J, Cantley LC: The evolution of phosphatidylinositol 3-kinases as regulators of growth and metabolism. Nat Rev Genet. 2006; 7(8): 606-619. PubMed Abstract | Publisher Full Text

2. Taniguchi $\mathrm{CM}$, Emanuelli B, Kahn CR: Critical nodes in signalling pathways: insights into insulin action. Nat Rev Mol Cell Biol. 2006; 7(2): 85-96. PubMed Abstract | Publisher Full Text

3. Fransson S, Uv A, Eriksson $\mathrm{H}$, et al:: $\mathbf{p} 37 \delta$ is a new isoform of PI3K p110 that increases cell proliferation and is overexpressed in tumors. Oncogene. 2012; 31(27): 3277-3286.

PubMed Abstract | Publisher Full Text

4. Ejeskär K, Vickes O, Kuchipudi A, et al:: The Unique Non-Catalytic C-Terminus of P37delta-PI3K Adds Proliferative Properties In Vitro and In Vivo. PLoS One. 2015; 10(5): e0127497.

PubMed Abstract | Publisher Full Text | Free Full Text

5. Foukas LC, Claret M, Pearce W, et al:: Critical role for the p110alpha phosphoinositide-3-OH kinase in growth and metabolic regulation. Nature. 2006; 441(7091): 366-370.

PubMed Abstract | Publisher Full Text

6. Knight ZA, Gonzalez B, Feldman ME, et al:: A pharmacological map of the PI3-K family defines a role for p110alpha in insulin signaling. Cell. 2006; 125(4): 733-747. PubMed Abstract | Publisher Full Text | Free Full Text

7. Sopasakis VR, Liu P, Suzuki R, et al:: Specific Roles of the p110alpha Isoform of Phosphatidylinsositol 3-Kinase in Hepatic Insulin Signaling and Metabolic Regulation. Cell Metab. 2010; 11(3): 220-230.

PubMed Abstract | Publisher Full Text | Free Full Text

8. Ciraolo $\mathrm{E}$, lezzi M, Marone $\mathrm{R}$, et al.: Phosphoinositide 3-kinase p110beta activity: key role in metabolism and mammary gland cancer but not development. Sci Signal. 2008; 1(36): ra3.

PubMed Abstract | Publisher Full Text | Free Full Text

9. Jia S, Liu Z, Zhang S, et al.: Essential roles of PI(3)K-p110beta in cell growth, metabolism and tumorigenesis. Nature. 2008; 454(7205): 776-779. PubMed Abstract | Publisher Full Text | Free Full Text

10. Patton DT, Garçon F, Okkenhaug K: The PI3K p110delta controls T-cell development, differentiation and regulation. Biochem Soc Trans. 2007; 35(Pt 2): 167-171. PubMed Abstract | Publisher Full Text

11. Bilancio A, Okkenhaug $\mathrm{K}$, Camps $\mathrm{M}$, et al:: Key role of the $\mathbf{p} 110$ delta isoform of PI3K in B-cell antigen and IL-4 receptor signaling: comparative analysis of genetic and pharmacologic interference with p110delta function in B cells. Blood 2006; 107(2): 642-650.

PubMed Abstract | Publisher Full Text

12. Eickholt BJ, Ahmed Al, Davies M, et al.: Control of axonal growth and regeneration of sensory neurons by the p110delta PI 3-kinase. PLoS One. 2007; 2(9): e869. PubMed Abstract | Publisher Full Text | Free Full Text

13. Ueki K, Algenstaedt $P$, Mauvais-Jarvis $F$, et al:: Positive and negative regulation of phosphoinositide 3-kinase-dependent signaling pathways by three different gene products of the p85alpha regulatory subunit. Mol Cell Biol. 2000; 20(21): 8035-8046.

PubMed Abstract | Publisher Full Text | Free Full Text

14. Taniguchi CM, Kondo $\mathrm{T}$, Sajan $\mathrm{M}$, et al:: Divergent regulation of hepatic glucose and lipid metabolism by phosphoinositide 3-kinase via Akt and PKClambda/ zeta. Cell Metab. 2006; 3(5): 343-353. PubMed Abstract | Publisher Full Tex

15. Luo J, Sobkiw CL, Hirshman MF, et al:: Loss of class $\mathrm{I}_{\mathrm{A}}$ PI3K signaling in muscle leads to impaired muscle growth, insulin response, and hyperlipidemia. Cell Metab. 2006; 3(5): 355-366.

PubMed Abstract | Publisher Full Text

16. Fruman DA, Mauvais-Jarvis F, Pollard DA, et al:: Hypoglycaemia, liver necrosis and perinatal death in mice lacking all isoforms of phosphoinositide 3-kinase p85 alpha. Nat Genet. 2000; 26(3): 379-382. PubMed Abstract | Publisher Full Text

17. Mauvais-Jarvis F, Ueki K, Fruman DA, et al.: Reduced expression of the murine p85alpha subunit of phosphoinositide 3-kinase improves insulin signaling and ameliorates diabetes. J Clin Invest. 2002; 109(1): 141-149.

PubMed Abstract | Publisher Full Text | Free Full Text

18. Terauchi $Y$, Tsuji $Y$, Satoh $S$, et al.: Increased insulin sensitivity and hypoglycaemia in mice lacking the $\mathrm{p} 85$ alpha subunit of phosphoinositide 3-kinase. Nat Genet. 1999; 21(2): 230-235. PubMed Abstract | Publisher Full Text

19. Brachmann SM, Ueki K, Engelman JA, et al.: Phosphoinositide 3-kinase catalytic subunit deletion and regulatory subunit deletion have opposite effects on insulin sensitivity in mice. Mol Cell Biol. 2005; 25(5): 1596-1607. PubMed Abstract | Publisher Full Text | Free Full Text

20. Barbour LA, Mizanoor Rahman S, Gurevich I, et al:: Increased P85alpha is a potent negative regulator of skeletal muscle insulin signaling and induces in vivo insulin resistance associated with growth hormone excess. J Biol Chem. 2005; 280(45): 37489-37494.

PubMed Abstract | Publisher Full Text

21. Ueki K, Fruman DA, Brachmann SM, et al:: Molecular balance between the regulatory and catalytic subunits of phosphoinositide 3-kinase regulates cell signaling and survival. Mol Cell Biol. 2002; 22(3): 965-977.

PubMed Abstract | Publisher Full Text | Free Full Text

22. Yu J, Zhang Y, Mcllroy J, et al.: Regulation of the p85/p110 phosphatidylinosito 3'-kinase: stabilization and inhibition of the p110alpha catalytic subunit by the p85 regulatory subunit. Mol Cell Biol. 1998; 18(3): 1379-1387. PubMed Abstract | Publisher Full Text | Free Full Text

23. Luo J, Field SJ, Lee JY, et al: The p85 regulatory subunit of phosphoinositide 3-kinase down-regulates IRS-1 signaling via the formation of a sequestration complex. J Cell Biol. 2005; 170(3): 455-464.

PubMed Abstract | Publisher Full Text | Free Full Text

24. Taniguchi CM, Tran TT, Kondo T, et al.: Phosphoinositide 3-kinase regulatory subunit p85alpha suppresses insulin action via positive regulation of PTEN. Proc Natl Acad Sci U S A. 2006; 103(32): 12093-12097. PubMed Abstract | Publisher Full Text | Free Full Text

25. Taniguchi CM, Aleman JO, Ueki K, et al.: The p85alpha regulatory subunit of phosphoinositide 3-kinase potentiates c-Jun $\mathrm{N}$-terminal kinase-mediated insulin resistance. Mol Cell Biol. 2007; 27(8): 2830-2840. PubMed Abstract | Publisher Full Text | Free Full Text

26. Zhao JJ, Cheng H, Jia S, et al:: The p110alpha isoform of PI3K is essential for proper growth factor signaling and oncogenic transformation. Proc Natl Acad Sci U S A. 2006; 103(44): 16296-16300. PubMed Abstract | Publisher Full Text | Free Full Text

27. Chaudhari A, Krumlinde D, Lundqvist A, et al.: p110 $\alpha$ Hot Spot Mutations E545K and H1047R Exert Metabolic Reprogramming Independently of p110 $\alpha$ Kinase Activity. Mol Cell Biol. 2015; 35(19): 3258-3273.

PubMed Abstract | Publisher Full Text | Free Full Text

28. Domin J, Pages F, Volinia S, et al.: Cloning of a human phosphoinositide 3kinase with a C2 domain that displays reduced sensitivity to the inhibitor wortmannin. Biochem J. 1997; 326(Pt 1): 139-147.

PubMed Abstract | Publisher Full Text | Free Full Text

29. Rozycka M, Lu YJ, Brown RA, et al:: cDNA cloning of a third human C2domain-containing class II phosphoinositide 3-kinase, PI3K-C2gamma, and chromosomal assignment of this gene (PIK3C2G) to 12p12. Genomics. 1998; 54(3): 569-574.

PubMed Abstract | Publisher Full Text

30. Bi L, Okabe I, Bernard DJ, et al:: Proliferative defect and embryonic lethality in mice homozygous for a deletion in the p110alpha subunit of phosphoinositide 3-kinase. J Biol Chem. 1999; 274(16): 10963-10968. PubMed Abstract | Publisher Full Text

31. Balla A, Balla T: Phosphatidylinositol 4-kinases: old enzymes with emerging functions. Trends Cell Biol. 2006; 16(7): 351-361. PubMed Abstract | Publisher Full Text

32. Ma H, Blake $\mathrm{T}$, Chitnis A, et al.: Crucial role of phosphatidylinositol 4-kinase Illalpha in development of zebrafish pectoral fin is linked to phosphoinositide 3-kinase and FGF signaling. J Cell Sci. 2009; 122(Pt 23): 4303-4310. PubMed Abstract | Publisher Full Text | Free Full Text

33. Funakoshi Y, Hasegawa H, Kanaho Y: Regulation of PIP5K activity by Arf6 and its physiological significance. J Cell Physiol. 2011; 226(4): 888-895. PubMed Abstract | Publisher Full Text

34. Jin N, Lang MJ, Weisman LS: Phosphatidylinositol 3,5-bisphosphate: regulation of cellular events in space and time. Biochem Soc Trans. 2016; 44(1): 177-184. PubMed Abstract | Publisher Full Text | Free Full Text

35. Shisheva A, Rusin B, Ikonomov OC, et al:: Localization and insulin-regulated relocation of phosphoinositide 5-kinase PIKfyve in 3T3-L1 adipocytes. J Biol Chem. 2001; 276(15): 11859-11869. PubMed Abstract | Publisher Full Text

36. Sbrissa D, Ikonomov $O$, Shisheva A: Selective insulin-induced activation of class $\mathrm{I}_{\mathrm{A}}$ phosphoinositide 3-kinase in PIKfyve immune complexes from 3T3-L1 adipocytes. Mol Cell Endocrinol. 2001; 181(1-2): 35-46. PubMed Abstract | Publisher Full Text

37. Shisheva A, Sbrissa D, Ikonomov O: Cloning, characterization, and expression of a novel $\mathrm{Zn}^{2+}$-binding FYVE finger-containing phosphoinositide kinase in insulin-sensitive cells. Mol Cell Biol. 1999; 19(1): 623-634. PubMed Abstract | Publisher Full Text | Free Full Text

38. Ikonomov OC, Sbrissa D, Delvecchio K, et al.: Muscle-specific Pikfyve gene disruption causes glucose intolerance, insulin resistance, adiposity, and hyperinsulinemia but not muscle fiber-type switching. Am J Physiol Endocrino Metab. 2013; 305(1): E119-131.

PubMed Abstract | Publisher Full Text | Free Full Text

39. Chaudhari A, Ejeskär K, Wettergren $\mathrm{Y}$, et al:: Dataset 1 in: Hepatic deletion of p110a and p85a results in insulin resistance despite sustained IRS1associated phosphatidylinositol kinase activity. F1000Research. 2017. Data Source

40. Chaudhari A, Ejeskär K, Wettergren Y, et al:: Dataset 2 in: Hepatic deletion of p110a and p85a results in insulin resistance despite sustained IRS1associated phosphatidylinositol kinase activity. F1000Research. 2017. Data Source

41. Chaudhari A, Ejeskär K, Wettergren Y, et al:: Dataset 3 in: Hepatic deletion of p110a and p85a results in insulin resistance despite sustained IRS1associated phosphatidylinositol kinase activity. F1000Research. 2017. Data Source

42. Chaudhari A, Ejeskär K, Wettergren $\mathrm{Y}$, et al.: Dataset 4 in: Hepatic deletion of p110a and p85a results in insulin resistance despite sustained IRS1associated phosphatidylinositol kinase activity. F1000Research. 2017. Data Source 


\section{Open Peer Review}

\section{Current Peer Review Status: ? ? ?}

\section{Version 1}

Reviewer Report 15 November 2017

https://doi.org/10.5256/f1000research.13447.r27377

(C) 2017 Lin R et al. This is an open access peer review report distributed under the terms of the Creative Commons Attribution License, which permits unrestricted use, distribution, and reproduction in any medium, provided the original work is properly cited.

\section{Richard Z. Lin}

Department of Physiology and Biophysics, Stony Brook School of Medicine, Stony Brook, NY, USA Lisa Ballou

Department of Physiology and Biophysics, Stony Brook School of Medicine, Stony Brook, NY, USA

\section{General Comments:}

The authors made a very interesting observation that L-DKO mice, lacking hepatic p110a and p85 $a$, have a milder metabolic phenotype than mice lacking only hepatic $p 110 a$. These mice have normal fasting blood glucose levels but not surprisingly they are glucose intolerant. Interestingly, the liver and WAT weights were reduced. Liver triglyceride levels were not measured to determine if the fat content of the liver was also reduced. Metabolic cage measurements would be revealing to rule in or out changes in energy expenditure of the animals. It would also be informative to know if a high-fat diet causes L-DKO animals to develop fasting hyperglycemia and/or if the fatty liver associated with this type of diet is accentuated or attenuated.

In general, the results from the insulin signaling experiments are not convincing. It is unclear why the authors concluded that the residual signaling to Akt is not due to Class I PI3Ks. IRS-1 pulldowns from L-DKO liver have substantial PI kinase activity. Better experiments are needed to resolve this research question (see comment below).

\section{Specific Comments:}

Figures $1 \mathrm{~F} \& 1 \mathrm{G}$, Figure 2 and Figure 3E. (a) The dose of insulin used to study insulin signaling was extremely high. $5 \mathrm{U}$ injected into a $30 \mathrm{~g}$ mouse is $167 \mathrm{U} / \mathrm{kg}$ body weight. Compare that to the 1.25 $\mathrm{U} / \mathrm{kg}$ body weight used for the insulin tolerance test. Some of the signaling changes could be due to activation of an unusually high percentage of insulin receptors or insulin activation of IGF1 receptors that would not occur under physiological conditions. Attempts to explain the pathophysiological phenotypes of the L-DKO mouse based on the signaling results is therefore problematic. (b) The legends say that "Basal conditions refer to fasting of mice overnight." Were the control mice anesthetized and injected ivc with saline, as stated under Methods? If so, the legends could be more specific. 
Figure 1F. Total Akt and total p70S6K should be shown.

Figure 1G. (a) Why did insulin treatment of control mice not increase the amount of p85a (or other regulatory subunit) associated with IRS-1? (b) Use of a pan p85 antibody to estimate changes in p85 $\beta$ expression is not convincing. Lack of a good mouse $p 85 \beta$ antibody is a limitation to the study. (c) The conclusion that similar amounts of IRS-1-bound $p 110 \beta$ were pulled down in control and L-DKO mice is not convincing based on the blot.

Figure 2. The conclusion that $\mathrm{p} 110 \beta$ and the other PI3Ks examined by western blotting are not responsible for the IRS-1-associated kinase activity is premature. The IPs should be assayed in the presence and absence of selective inhibitors to determine the contribution of $p 110 \beta$ and the other enzymes to the PI kinase activity. Considering that hepatocytes make up $75-80 \%$ of the cell types in the liver, it is also possible that some of the kinase activity in the IRS-1 IP comes from p110a in the $20-25 \%$ of cells that are not targeted by albumin-Cre.

Figure 3. Histological examination of the livers should be included. Liver triglyceride levels should be measured.

Figures 3C \& 3D. The specific WAT depots and muscles examined should be identified.

Figure 4A-D. Fasting insulin is higher in the L-DKO mice at 10 weeks of age. Presumably, this is why these mice are euglycemic. Insulin levels should be measured before and after the glucose challenge with mice in one of the GTT age groups. This experiment will assess if the glucose intolerance is due to inability of the L-DKO mice to mount a further insulin response.

Is the work clearly and accurately presented and does it cite the current literature? Yes

Is the study design appropriate and is the work technically sound?

Yes

Are sufficient details of methods and analysis provided to allow replication by others? Yes

If applicable, is the statistical analysis and its interpretation appropriate? Yes

Are all the source data underlying the results available to ensure full reproducibility? Partly

Are the conclusions drawn adequately supported by the results?

Partly

Competing Interests: No competing interests were disclosed.

We confirm that we have read this submission and believe that we have an appropriate level of expertise to confirm that it is of an acceptable scientific standard, however we have 


\section{significant reservations, as outlined above.}

\section{Author Response 21 May 2018}

Victoria Rotter Sopasakis, University of Gothenburg, Gothenburg, Sweden

Response to general comments:

We agree with the reviewers that all these studies would be very interesting, but would take several years to complete and is outside the scope of this particular study.

Response to specific comments:

1a. The dose of insulin used is what is normally used for these types of experiments. If the reviewers would be right, i.e unusually high activation of insulin would occur, this would be the case in all our other similar studies (and all other scientists' studies who are doing similar experiments), for example in the study where we knocked out p110a in the liver. Since this is not the case, we don't believe that this a major problem for the interpretation of our data.

1b. Yes, the control mice were anesthetized and injected ivc with saline (basal conditions) or insulin. This has been added to the figure legends as required.

\section{Total Akt and total p70S6K blots have been added to Figure 1F.}

3a. We have added more experiments to this figure $(n=4)$ and made quantitative graphs of the results. The amount of p85a associated with IRS1 still remains similar between basal and insulin-stimulated conditions, whereas the p85-pan antibody shows increased amounts of total p85 in response to insulin (figures $1 \mathrm{~N}$ and 10 ).

3b. We have previously (before submitting the manuscript) tried various different $\mathrm{p} 85 \mathrm{~b}$ antibodies without any success. Some work well for human tumor tissue for example, but give no band at all for our mouse liver lysates. Other antibodies we tried fail to deliver a band for both human and mouse tissues. This is the reason we chose to use the p85-pan antibody to indirectly show p85b protein expression. Since both Dr Woodgett and Drs Lin and Ballou requested a p85b antibody we have tried again to make various $\mathrm{p} 85 \mathrm{~b}$ antibodies on the market to work for our liver lysates and have spent months now trying to optimize the western blot conditions for these antibodies. We are not satisfied with the results. The only conclusion we can draw is that either 1 ) the p85b antibodies available on the market simply does not work well for mouse tissue or 2) there is not much p85b expressed in mouse liver. Based on the p85-pan westerns that we performed as well as previous studies including Taniguchi et al, we believe that there simply is not that much p85b expressed in mouse liver.

3c. More experiments have been added $(n=4)$ and quantifying graphs are now included in the figure (figure $1 \mathrm{M}$ ).

4. These types of experiments are all very interesting. However, they are complicated, particularly considering that inhibitors are never $100 \%$ selective and specific. We therefore question the gain of these experiments in relation to the work and resources that have to 
be invested to complete them.

5. Histological experiments and liver triglyceride level measurements are outside the scope of this study.

6. These types of experiments would not lead to increased understanding of the underlying mechanisms of our data. We therefore question the gain of these experiments in relation to the work and resources that have to be invested to complete them.

7. It is quite possible that the L-DKO mice are not able to further increase the insulin secretion is response to the glucose load in the GTT considering the very high insulin levels these mice have normally. We have added a glucagon ELISA (new figure $4 \mathrm{H}$ ) that shows normal glucagon levels for DKO mice both at $10 \mathrm{w}$ of age and $24 \mathrm{w}$ of age. The normal glucagon levels and the very high insulin levels in the DKO mice indicates that the pancreas is working normally in these mice and the underlying mechanism for the glucose intolerance is therefore not likely at the level of the pancreas.

Competing Interests: No competing interests were disclosed.

Reviewer Report 08 November 2017

https://doi.org/10.5256/f1000research.13447.r27376

(C) 2017 Dong L. This is an open access peer review report distributed under the terms of the Creative Commons Attribution License, which permits unrestricted use, distribution, and reproduction in any medium, provided the original work is properly cited.

\section{Lily Q. Dong}

Department of Cell Systems \& Anatomy, University of Texas Health at San Antonio, San Antonio, TX, USA

Chaudhari et al. reported the physiologic roles of hepatic p110a and p85a in regulating insulin signaling and glucose homeostasis. They concluded that hepatic deletion of p110a and p85a (LDKO) led to mild metabolic phenotype of the L-DKO mice and proposed that lipid kinases other than PI3Ks might compensate for the loss of $\mathrm{p} 110 \mathrm{a} / \mathrm{p} 85 \mathrm{a}$ by signaling through unknown signaling pathway other than Akt signaling. Since deletion of p85a leads to improved insulin sensitivity and deletion of p110a leads to impaired insulin signaling and insulin resistance, it is interesting to learn that L-DKO mice showed an overall less severe metabolic phenotype compared to the Lp110a KO mice.

1. Although the expression levels of p110b were decreased in the liver of L-DKO mice (Fig. 1E), IRS1-associated p110b levels were comparable between the control and KO mice (Fig. 1G). 
In addition, notable levels of $\mathrm{p} 110 \mathrm{~b}$ activity were maintained in the L-DKO mice and insulin treatment can stimulate the activity although it is $50 \%$ compared to the control (Fig. 2B). It is unclear why the authors concluded that the intact IRS1-associated kinase activity in the KO mice are not from the remaining $\mathrm{p} 110 \mathrm{~b}$.

2. The KO mice showed significantly impaired glucose tolerance and markedly increased fasting insulin levels (Fig. 4). What were the pancreatic phenotype of the KO mice? What were the levels of glucagon in the KO mice?

Is the work clearly and accurately presented and does it cite the current literature? Yes

Is the study design appropriate and is the work technically sound? Yes

Are sufficient details of methods and analysis provided to allow replication by others? Yes

If applicable, is the statistical analysis and its interpretation appropriate?

Yes

Are all the source data underlying the results available to ensure full reproducibility? Yes

Are the conclusions drawn adequately supported by the results?

Partly

Competing Interests: No competing interests were disclosed.

I confirm that I have read this submission and believe that I have an appropriate level of expertise to confirm that it is of an acceptable scientific standard, however I have significant reservations, as outlined above.

Author Response 21 May 2018

Victoria Rotter Sopasakis, University of Gothenburg, Gothenburg, Sweden

1. We don't believe that the intact IRS1-associated kinase activity in the DKO mice are from the remaining $\mathrm{p} 110 \mathrm{~b}$ for the following reasons:

The total degree of kinase activity is very much smaller for $\mathrm{p} 110 \mathrm{~b}$ compared to $\mathrm{p} 110 \mathrm{a}$. This is an observation we have made over and over again for liver lysates in response to insulin in several different studies (the a.u numbers of the $y$-axis in the graphs in figure 2 demonstrates this to some extent). However, we still wanted to be sure that we were correct to rule out a role of $\mathrm{p} 110 \mathrm{~b}$ since we observed similar amounts of $\mathrm{p} 110 \mathrm{~b}$ bound to IRS1 in the DKO and controls. It was therefore important to look at the kinase activity associated with IRS1. The p110b-associated kinase activity in response to insulin was significantly decreased in the DKO mice compared to controls (figure $2 \mathrm{~b}$ ). These two 
observations ( 1 ) very much smaller degree of $\mathrm{p} 110 \mathrm{~b}$ activity over all compared to $\mathrm{p} 110 \mathrm{a}$ kinase activity and 2) decreased IRS1-associated p110b activity in the DKO in response to insulin) makes it highly inlikely that the sustained IRS1-associated kinase activity is due to compensatory levels of $\mathrm{p} 110 \mathrm{~b}$ kinase activity).

2. We have performed a glucagon ELISA assay for the mice (new figure $4 \mathrm{H}$ ). There were no differences in glucagon serum levels between DKO mice and controls at either 10 weeks of age or 24 weeks of age. The high fasting insulin levels in the DKO mice suggest that insulin production and secretion by the pancreas is intact and since no differences in glucagon secretion was observed even at older age we conclude that the pancreatic phenotype is likely very similar between DKO mice and controls.

Competing Interests: No competing interests were disclosed.

Reviewer Report 14 September 2017

https://doi.org/10.5256/f1000research.13447.r25513

(c) 2017 Woodgett J et al. This is an open access peer review report distributed under the terms of the Creative Commons Attribution License, which permits unrestricted use, distribution, and reproduction in any medium, provided the original work is properly cited.

\section{James R. Woodgett}

Lunenfeld-Tanenbaum Research Institute, Sinai Health System \& University of Toronto, Toronto, ON, Canada

\section{Prital Patel}

Lunenfeld-Tanenbaum Research Institute, Sinai Health System \& University of Toronto, Toronto, ON, Canada

In this study, the authors generated a liver-specific double knockout of the regulatory and catalytic subunit of Class 1A PI3K. Previously, single inactivation of either the catalytic art regulatory subunits had been shown to result in opposite effects on insulin resistance vs sensitivity. The authors demonstrated through in vivo studies in male mice (129Sv-C57BI/6) that defects in glucose tolerance as well as changes in liver, fat and body weight occur upon deletion of both the regulatory PIK3R1 (p85a) and catalytic subunit PIK3CA (p110a) but retained normal production of gulches from the liver.

\section{Specific Comments:}

1. Figure 1E (page 6): the authors state (on page 5 ) that low levels of $p 85 \beta$ were detected in the L-DKO mice compared to controls. This was indirectly demonstrated through the use of a pan-p85 antibody that detects both p85a and p85 $\beta$. Mice with liver-specific deletion of p85a on a $885 \beta$ null background have been previously characterized (Taniguchi et al.). There, the overall levels of $p 85 \beta$ detected utilizing a pan $p 85 \beta$ antibody in a lysate derived from a liver that was wild type for $p 85 \beta$ and null for p85a was minimal. Therefore, it is possible that the 
overall protein content reduction observed using the pan p85 antibody in Figure1E may be explained by the deletion of p85a from the liver, and may not be due to any change in $p 85 \beta$ levels. To directly compare wild type and L-DKO samples, a specific $p 85 \beta$ antibody should be used. Loading controls should also be provided for some panels in Figure 1.

2. Figure $1 \mathrm{~F}$ to show impaired activation, total AKT blots should be provided (similar to Figure $3 \mathrm{E})$. Total levels of p70S6K also need to be measured. In Figure 1G, the authors state that although p110 $\beta$ levels are reduced, the amount associated with IRS-1 is unchanged. However, due to the variability across samples in both control and L-DKO, and the overall poor quality of the blot, these conclusions don't inspire confidence. These data should be quantitated. Additionally, the $p 110 \beta$ band on the last lane appears to run slightly higher compared to the rest of the bands and the control raising possible questions over the specificity of the $p 110 \beta$ antibody used for IP. Are similar results observed using a distinct antibody? In line with the comments in point 1 , the authors state that the overall amount of p85 $\beta$ associated IRS- 1 does not change. This conclusion requires use of a p85 $\beta$ selective antibody.

3. As noted by the authors, there is known complexity between the structural roles of the various PI3K subunits and isoforms, with effects on protein stability and access to IRS-1 binding sites. There appears, as noted above, to be significant variation in levels of the untargetted subunits across the 2 typically shown animals (e.g. Figure $1 \mathrm{G}$ ). If other animals were measured, a composite of the levels (e.g. $n=4$ ) would provide much better insight into the levels (if any) of compensation, allowing a clearer picture of what may be underlying the glucose metabolic effects. It is also possible there was downstream adaptation given the IRS-1 is negatively regulated by PI3K signaling (and appears somewhat higher in the DKOs (Figure 1G).

4. For the PI3K lipid kinase activity measurements (chromatographic separation, Figure 2 shows the quantitation), how were the separate plates normalized?

Minor grammatical error:

Page 11, second paragraph line 10- "and" is added in error.

*Taniguchi, C. M., T. Kondo, M. Sajan, J. Luo, R. Bronson, T. Asano, R. Farese, L. C. Cantley and C. R. Kahn (2006). "Divergent regulation of hepatic glucose and lipid metabolism by phosphoinositide 3kinase via Akt and PKClambda/zeta." Cell Metab 3(5): 343-353.

Is the work clearly and accurately presented and does it cite the current literature? Yes

Is the study design appropriate and is the work technically sound? Partly

Are sufficient details of methods and analysis provided to allow replication by others? Yes

If applicable, is the statistical analysis and its interpretation appropriate? 
Partly

Are all the source data underlying the results available to ensure full reproducibility? Yes

Are the conclusions drawn adequately supported by the results?

Yes

Competing Interests: No competing interests were disclosed.

Reviewer Expertise: Signal transduction

We confirm that we have read this submission and believe that we have an appropriate level of expertise to confirm that it is of an acceptable scientific standard, however we have significant reservations, as outlined above.

Author Response 21 May 2018

Victoria Rotter Sopasakis, University of Gothenburg, Gothenburg, Sweden

1. We totally agree with the Dr Woodgett's point here and it is essentially what we tried to convey in the manuscript, but to make it clearer we have added an extra sentence including the reference to Taniguchi et al (page 9, row 7).

We have previously (before submitting the manuscript) tried various different p85b antibodies without any success. Some work well for human tumor tissue for example, but give no band at all for our mouse liver lysates. Other antibodies we tried fail to deliver a band for both human and mouse tissues. This is the reason we chose to use the p85-pan antibody to indirectly show p85b protein expression. Since both Dr Woodgett and Drs Lin and Ballou requested a p85b antibody we have tried again to make various $\mathrm{p} 85 \mathrm{~b}$ antibodies on the market to work for our liver lysates and have spent months now trying to optimize the western blot conditions for these antibodies. We are not satisfied with the results. The only conclusion we can draw is that either 1) the p85b antibodies available on the market simply does not work well for mouse tissue or 2) there is not much p85b expressed in mouse liver (just as Dr Woodgett points out above). Based on the p85-pan westerns that we performed as well as previous studies including Taniguchi et al, to which Dr Woodgett referred, we believe that there simply is not that much p85b expressed in mouse liver. Loading controls have been added to figure $1 \mathrm{E}$ and $1 \mathrm{~F}$, including Akt and p70S6K.

2.

Total Akt blot has been added to figure $1 \mathrm{~F}$

Total p7056K has been added to figure $1 \mathrm{~F}$

Blots in figure $1 \mathrm{G}$ (=new figure $1 \mathrm{~K}$ ) have been quantitated, except for $\mathrm{p} 110 \mathrm{~d}$, which is so weak there is no point to quantify it. Graphs of the quantitation have been added to figure 1 (new figures $1 \mathrm{~L}-\mathrm{P}$ ). $\mathrm{n}=4$ in these quantification graphs, i.e we have added more samples for each condition to cover small variations in the immunoprecipitation and western blot experiments.

$\mathrm{p} 85 \mathrm{~b}$ has not been added for the same reason as in figure $1 \mathrm{E}$, see above. 
3.

In the quantification graphs added to figure $1 \mathrm{~F}$ (new figure $1 \mathrm{G}-\mathrm{J}$ ) $\mathrm{n}=4$, ie we have added new experiments with different samples. The WB pictures become very large when adding so many panels, so we decided including all four replicates in the quantification graphs. However, all blots are provided in the raw data sets for the referee to see.

Same for figure $1 \mathrm{G}$ (new figure $1 \mathrm{~K}$ ), i.e $\mathrm{n}=4$. Quantification graphs have been added (new figures $1 \mathrm{~L}-\mathrm{P}$ ).

4. The plates were normalized to a reference sample $=$ active $\mathrm{p} 110 \mathrm{a} / \mathrm{p} 85 \mathrm{complex}$ (see original plate pictures in the raw data sets).

5. Can not find this error. Please specify.

Competing Interests: No competing interests were disclosed.

The benefits of publishing with F1000Research:

- Your article is published within days, with no editorial bias

- You can publish traditional articles, null/negative results, case reports, data notes and more

- The peer review process is transparent and collaborative

- Your article is indexed in PubMed after passing peer review

- Dedicated customer support at every stage

For pre-submission enquiries, contact research@f1000.com 